\title{
Nanobody-Mediated Neutralization Reveals an Achilles Heel for Norovirus
}

\author{
Anna D. Koromyslova, ${ }^{a, b}$ Jessica M. Devant, ${ }^{a, b}$ Turgay Kilic, $^{\text {a,b }}$ Charles D. Sabin, ${ }^{\text {a,b }}$ Virginie Malak, $^{\text {a,b }}$ (D) Grant S. Hansman ${ }^{a, b}$ \\ aSchaller Research Group at the University of Heidelberg and DKFZ, Heidelberg, Germany \\ bDepartment of Infectious Diseases, Virology, University of Heidelberg, Heidelberg, Germany
}

Anna D. Koromyslova and Jessica M. Devant contributed equally to this work. Author order was determined by their contribution to the final data and manuscript.

ABSTRACT Human norovirus frequently causes outbreaks of acute gastroenteritis. Although discovered more than five decades ago, antiviral development has, until recently, been hampered by the lack of a reliable human norovirus cell culture system. Nevertheless, a lot of pathogenesis studies were accomplished using murine norovirus (MNV), which can be grown routinely in cell culture. In this study, we analyzed a sizeable library of nanobodies that were raised against the murine norovirus virion with the main purpose of developing nanobody-based inhibitors. We discovered two types of neutralizing nanobodies and analyzed the inhibition mechanisms using X-ray crystallography, cryo-electron microscopy (cryo-EM), and cell culture techniques. The first type bound on the top region of the protruding $(P)$ domain. Interestingly, this nanobody binding region closely overlapped the MNV receptorbinding site and collectively shared numerous $\mathrm{P}$ domain-binding residues. In addition, we showed that these nanobodies competed with the soluble receptor, and this action blocked virion attachment to cultured cells. The second type bound at a dimeric interface on the lower side of the $\mathrm{P}$ dimer. We discovered that these nanobodies disrupted a structural change in the capsid associated with binding cofactors (i.e., metal cations/bile acid). Indeed, we found that capsids underwent major conformational changes following addition of $\mathrm{Mg}^{2+}$ or $\mathrm{Ca}^{2+}$. Ultimately, these nanobodies directly obstructed a structural modification reserved for a postreceptor attachment stage. Altogether, our new data show that nanobody-based inhibition could occur by blocking functional and structural capsid properties.

IMPORTANCE This research discovered and analyzed two different types of MNVneutralizing nanobodies. The top-binding nanobodies sterically inhibited the receptorbinding site, whereas the dimeric-binding nanobodies interfered with a structural modification associated with cofactor binding. Moreover, we found that the capsid contained a number of vulnerable regions that were essential for viral replication. In fact, the capsid appeared to be organized in a state of flux, which could be important for cofactor/receptor-binding functions. Blocking these capsid-binding events with nanobodies directly inhibited essential capsid functions. Moreover, a number of MNV-specific nanobody binding epitopes were comparable to human norovirusspecific nanobody inhibitors. Therefore, this additional structural and inhibition information could be further exploited in the development of human norovirus antivirals.

KEYWORDS nanobodies, capsid, neutralization, noroviruses

orovirus belongs to the Caliciviridae family of nonenveloped, single-stranded, positive-sense RNA viruses (1). The Norovirus genus comprises at least seven genogroups (GI to GVII), where GI, GII, and GIV infect humans (2). Worldwide, human norovirus is one of the leading causes of outbreaks of acute gastroenteritis (3-5). There
Citation Koromyslova AD, Devant JM, Kilic T, Sabin CD, Malak V, Hansman GS. 2020. Nanobody-mediated neutralization reveals an Achilles heel for norovirus. J Virol 94:e00660-20. https://doi.org/10.1128/JVI.00660-20.

Editor Rozanne M. Sandri-Goldin, University of California, Irvine

Copyright $\odot 2020$ American Society for Microbiology. All Rights Reserved. Address correspondence to Anna D. Koromyslova, anna.koromyslova@gmail.com, or Grant S. Hansman, g.hansman@dkfz.de.

Received 14 April 2020

Accepted 14 April 2020

Accepted manuscript posted online 22 April 2020

Published 16 June 2020 
are still no antivirals or vaccines for norovirus. Moreover, clinical trials with norovirus virus-like particle (VLP) vaccines have had limited success (6-8).

Caliciviruses also infect other animals and include rabbit hemorrhagic disease virus (RHDV), feline calicivirus (FCV), and murine norovirus (MNV). Pathogenic studies using MNV have provided an abundance of neutralization, vaccine development, and pathogenesis information, since MNV is grown routinely in cell culture and a reliable reverse genetics system is available (9-11).

Structural studies have shown that the virion capsid (VP1) has a T=3 icosahedral symmetry. The capsid comprises 180 VP1 copies, which are structured in three quasiequivalent subunits that fold into $A / B$ and $C / C$ dimers (12). VP1 can be divided into two domains, termed shell $(S)$ and protruding $(P)$ domains. The $S$ domain forms the inner core and surrounds the viral RNA. The $\mathrm{P}$ domain forms protruding spikes and contains the main determinants for host binding factors, which can include binding sites for histo-blood group antigens (HBGAs), bile acids, bivalent metal cations, and the receptor CD300lf (13-19). The P domain is further divided into two subdomains: a distal P2 subdomain and a lower $\mathrm{P} 1$ subdomain that is connected to the $\mathrm{S}$ domain via a flexible hinge region $(12,20-22)$.

Unfortunately, limited research is focused on the discovery of norovirus antivirals. Nevertheless, different steps in the replication cycle, including cell attachment and entry, replication and translation, and virion assembly, offer many ideal targets. A lot of antiviral development is targeted against the capsid, especially regions that bind cofactors. Recent studies discovered human norovirus-specific monoclonal antibodies (MAbs) and nanobodies that sterically blocked the HBGA pocket (23-28). Other studies using MNV showed that blocking the MNV CD300lf receptor-binding pocket with MNV-specific MAbs inhibited viral replication (18, 29, 30).

In this study, we screened a large library of MNV-specific nanobodies in order to identify nanobody-based inhibitors. We found several candidates that block replication, and the structural basis of neutralization was analyzed. Overall, our findings exposed crucial roles of capsid conformational modifications and described two nanobodybased inhibition mechanisms.

\section{RESULTS}

Nanobody neutralizing and binding capacities. A library of 58 MNV virion-specific nanobodies was analyzed in order to identify candidates that presented superior neutralizing and binding properties. A total of 51 distinct nanobody families (based on CDR sequence diversity) was produced and analyzed. In an attachment assay, most nanobodies reduced the number of MNV plaques, where 38 had greater than $70 \%$ inhibition at $20 \mu \mathrm{g} / \mathrm{ml}$ (Fig. 1A). Fifteen nanobodies reduced the number of plaques by more than $75 \%$ at $2 \mu \mathrm{g} / \mathrm{ml}$ (Fig. 1B). Dilution inhibition curves of these nanobodies yielded $50 \%$ inhibitory concentration $\left(\mathrm{IC}_{50}\right.$ ) values ranging between 0.03 to $1.6 \mu \mathrm{g} / \mathrm{ml}$, where NB-5867 and NB-5894 were the most effective $\left(\mathrm{IC}_{50}=0.03\right.$ and $0.09 \mu \mathrm{g} / \mathrm{ml}$, respectively) (Fig. 1C and Table 1). Enzyme-linked immunosorbent assay (ELISA) data showed that these nanobodies bound strongly to virions, having cutoff concentrations ranging between 0.9 and $5.7 \mathrm{ng} / \mathrm{ml}$ (Table 1).

The binding properties for eight nanobodies were further analyzed using isothermal titration calorimetry (ITC) and affinity values $\left(K_{d}\right)$ ranging between 0.03 to $13.9 \mathrm{nM}$ (Table 1). The binding reactions were exothermic and were fitted into a one-site binding model (stoichiometry value, $\sim 1$ ). However, the entropy contribution was variable, even between nanobodies from the same family, and ranged between -33 and $32 \mathrm{~kJ} / \mathrm{mol}$. Overall, these neutralizing and binding results revealed that several nanobodies had high affinities and strong neutralization capacities.

$\mathbf{X}$-ray crystal structures of $\mathbf{P}$ domain and nanobody complexes. In order to show how neutralizing nanobodies bound to the capsid, the X-ray crystal structures of MNV $P$ domain and nanobody complexes were determined (Table 2). The electron densities of the $\mathrm{P}$ domain and nanobody complexes were well resolved, and water molecules were observed in all structures. The overall structure of the $\mathrm{P}$ domain in all complex 
A
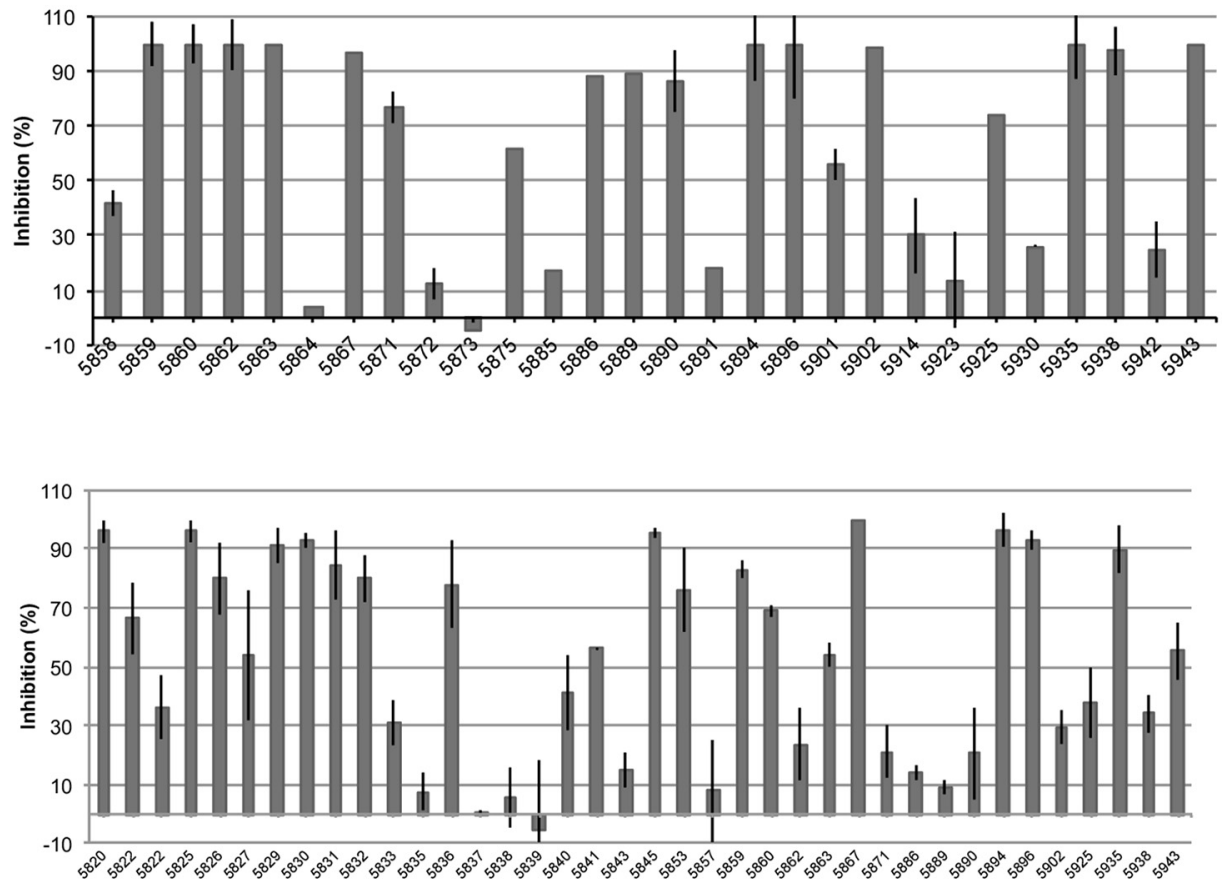

B
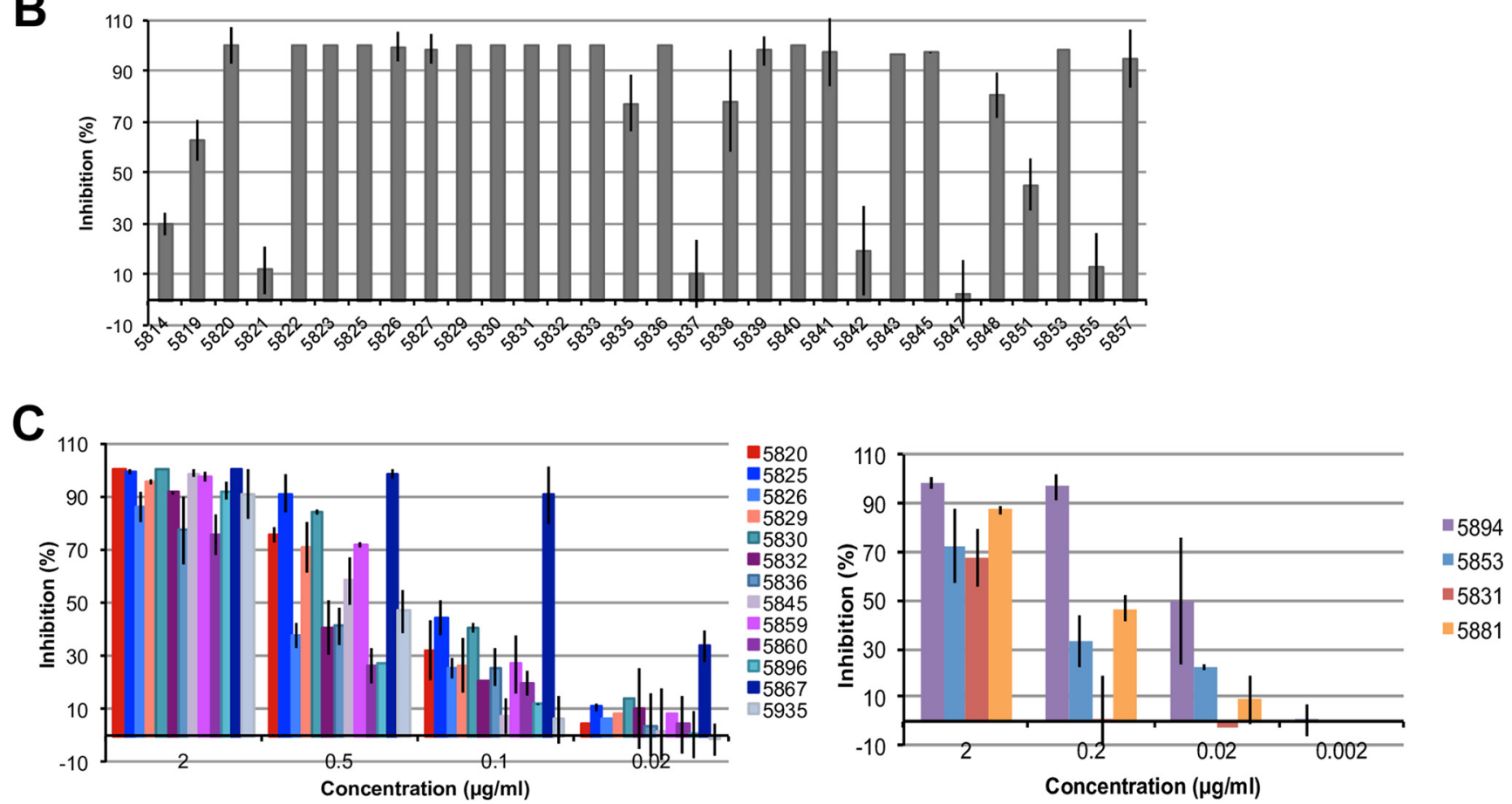

FIG 1 (A) The neutralization capacities of nanobodies were analyzed in an attachment assay. Nanobodies were tested at $20 \mu \mathrm{g} / \mathrm{ml}$. In total, 38 of 58 nanobodies showed inhibition greater than $70 \%$. All experiments were performed in triplicate, and the standard deviation is shown. (B) At $2 \mu \mathrm{g} / \mathrm{ml}, 15$ nanobodies showed more than 70\% inhibition. (C) MNV neutralization was tested with serially diluted (1:4 or 1:10) nanobodies, with a starting concentration of $2 \mu \mathrm{g} / \mathrm{ml}$. Nanobodies had $\mathrm{IC}_{50}$ values ranging between 0.03 and $1.6 \mu \mathrm{g} / \mathrm{ml}$. All experiments were performed three times, in triplicate, and the standard deviation is shown.

structures was highly similar to the apo P domain except for several loop movements. All nanobodies had the typical immunoglobulin fold, and the CDRs primarily interacted with the P domain. Two nanobodies (NB-5853 and NB-5867) bound on the top of the P2 subdomain, and two nanobodies (NB-5820 and NB-5829) bound at the dimeric interface on the side of the P1 subdomain (Fig. 2). 
TABLE 1 Summary of characterized nanobodies ${ }^{a}$

\begin{tabular}{|c|c|c|c|c|c|c|c|c|}
\hline Family & Nanobody & $\begin{array}{l}\text { Binding } \\
\text { (ng/ml) }\end{array}$ & $I C_{50}(\mu \mathrm{g} / \mathrm{ml})$ & Binding site & EM & $K_{d}(\mathrm{M})$ & $\mathrm{dH}(\mathrm{kJ} / \mathrm{mol})$ & -TdS (kJ/mol) \\
\hline 1 & 5820 & 1.68 & 0.20 & Bottom & & $8.19 \mathrm{E}^{-10} \pm 3.16 \mathrm{E}^{-10}$ & $-37.45 \pm 1.44$ & $-14.54 \pm 2.38$ \\
\hline 1 & 5825 & 3.41 & 0.11 & & & $1.38 \mathrm{E}^{-9} \pm 1.20 \mathrm{E}^{-9}$ & $-54.37 \pm 0.88$ & $3.08 \pm 1.51$ \\
\hline 1 & 5826 & 2.21 & 0.73 & & & & & \\
\hline 1 & 5845 & 2.83 & 0.43 & Bottom & & $1.79 \mathrm{E}^{-9} \pm 4.38 \mathrm{E}^{-10}$ & $-73.24 \pm 6.41$ & $20.71 \pm 7.80$ \\
\hline 1 & 5859 & 2.53 & 0.24 & Bottom & & $7.80 \mathrm{E}^{-10} \pm 6.27 \mathrm{E}^{-10}$ & $-21.50 \pm 1.03$ & $-30.98 \pm 2.09$ \\
\hline 2 & 5822 & 1.63 & $<75^{b}$ & Bottom & & & & \\
\hline 2 & 5831 & 2.33 & 1.59 & & & & & \\
\hline 2 & 5860 & 2.64 & 1.15 & & & & & \\
\hline 5 & 5896 & 2.94 & 0.97 & & & & & \\
\hline 10 & 5836 & 1.30 & 0.63 & & & & & \\
\hline 13 & 5829 & 2.09 & 0.25 & Bottom & & $1.41 \mathrm{E}^{-9} \pm 3.12 \mathrm{E}^{-10}$ & $-17.16 \pm 2.45$ & $-33.38 \pm 1.85$ \\
\hline 15 & 5867 & 1.71 & 0.03 & Top & Aggregates & $1.39 \mathrm{E}^{-8} \pm 8.97 \mathrm{E}^{-9}$ & $-59.10 \pm 1.63$ & $13.87 \pm 3.33$ \\
\hline 15 & 5894 & 1.16 & 0.09 & Top & & $6.83 \mathrm{E}^{-9} \pm 1.57 \mathrm{E}^{-9}$ & $-78.63 \pm 0.24$ & $31.94 \pm 0.88$ \\
\hline 18 & 5935 & 4.35 & 0.57 & Bottom & & & & \\
\hline 19 & 5853 & 0.92 & 1.15 & Top & Aggregates & & & \\
\hline 37 & 5833 & 5.69 & $<30^{b}$ & Bottom & & & & \\
\hline 39 & 5830 & 2.83 & 0.14 & & & $3.44 \mathrm{E}^{-11} \pm 1.43 \mathrm{E}^{-11}$ & $-28.17 \pm 0.95$ & $-31.71 \pm 0.15$ \\
\hline 50 & 5863 & 4.18 & $<75^{b}$ & Bottom & & & & \\
\hline 52 & 5890 & 5.02 & $<30^{b}$ & Bottom & & & & \\
\hline
\end{tabular}

${ }^{a}$ Nanobodies were sorted by family and nanobody number. Shown are the cutoff values for binding as determined by ELISA, the IC ${ }_{50}$ values as determined by attachment assay, the binding site of the nanobody, and the nanobody aggregation ability as observed using EM. The $K_{d}$, dH, and -TdS values (plus standard deviations) for eight nanobodies tested using ITC are given.

${ }^{b}$ Mean percent inhibition at $2 \mu \mathrm{g} / \mathrm{ml}$.

Structure of the MNV P domain and NB-5853 complex. The X-ray crystal structure of the $\mathrm{P}$ domain and NB-5853 complex was solved to $1.96-\AA$ resolution. A network of hydrogen bonds was formed between the $P$ domain and NB-5853 (Fig. 3A). The majority of NB-5853 binding residues were located in CDR3. Five $P$ domain residues (Q334, G400, E356, T362, and N364) formed eight direct hydrogen bonds with NB-5853 residues. Furthermore, five $P$ domain residues (T301, V304, A365, F375, and Y399) were involved in hydrophobic interactions with NB-5853 residues. Additionally, a number of water-mediated bonds were formed with the P domain and NB-5853. Overall, these findings showed that this nanobody was held tightly by one $\mathrm{P}$ domain monomer.

Remarkably, the NB-5853 binding site closely overlapped the MNV CD300lf receptor footprint (Fig. 4). In fact, NB-5853 interacted with nine $P$ domain residues that held CD300If (T301, V304, Q334, E356, N364, F375, S377, Y399, and I358). Moreover, NB-5853 binding resulted in a $\mathrm{P}$ domain conformational change comparable to binding soluble CD300If, i.e., in loops covering residues 341 to 351 and 360 to 370 . One of these loops (341 to 351) was "closed" in apo P domains and "open" when CD300lf was bound (16, 31). These findings indicated that NB-5853 bound to the $P$ domain similarly to the soluble receptor. Moreover, these results suggest that NB-5853 might directly interfere with CD300lf binding.

Structure of the MNV P domain and NB-5867 complex. The X-ray crystal structure of the $\mathrm{P}$ domain in complex with NB-5867 was solved to $2.19-\AA \AA$ resolution. The binding site of NB-5867 was closely similar to NB-5853 (Fig. 4) except for an additional hydrogen bond provided by a residue (D348) on the other monomer. All three CDRs of NB-5867 were involved in binding (Fig. 3B) Eight $P$ domain residues (T301, Q334, T363, N364, S377, T379, Y399, and D348monomer2) formed 14 direct hydrogen bonds with NB-5867 residues. Five $P$ domain residues (T301, V304, 1358, F375, and Y399) were involved in hydrophobic interactions with NB-5867 residues, and a number of water-mediated bonds provided additional interactions between the two proteins. In summary, these results showed that NB-5867 was tightly held by mostly one P domain monomer.

NB-5867 interacted with nine P domain residues that also bound CD300lf (T301, V304, Q334, E356, I358, N364, F375, S377, and Y399) (Fig. 4). Moreover, the loops covering residues 341 to 351 and 360 to 370 shifted into an equivalent position as in the NB-5853 and CD300lf complexes. Overall, these findings showed that the top- 
TABLE 2 Summary of X-ray crystallography data collection and refinement

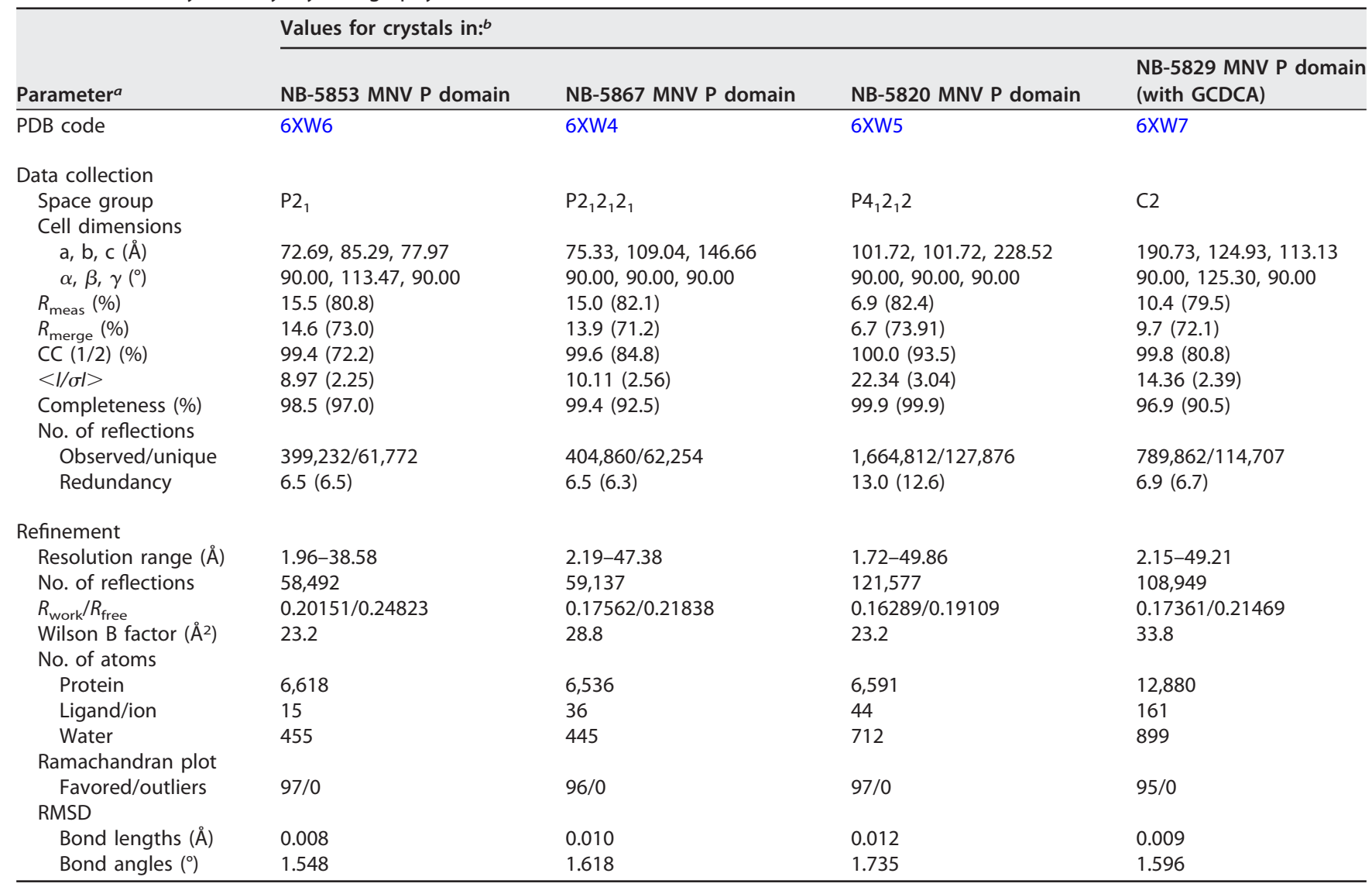

${ }^{a} R_{\text {meas }}$, redundancy-independent merging $R$ factor; $R_{\text {merge }}=\Sigma|I-\langle I\rangle| \Sigma \mid \times 100$, where $l$ is the intensity of a reflection and $\langle>$ is the average intensity; CC $(1 / 2)$, Pearson's correlation coefficient; $\left\langle|/ \sigma|>\right.$, signal-to-noise ratio. $R_{\text {free }}$ was calculated from $5 \%$ of randomly selected data for cross-validation. $R=\Sigma\left|F_{o}-F_{\mathrm{c}}\right| \Sigma\left|F_{\mathrm{o}}\right| \times$ 100. RMSD, root mean square deviation.

${ }^{b}$ Numbers in parentheses refer to the highest-resolution shell.

binding nanobodies overlapped the CD300lf binding site and inhibition could interfere with receptor-binding events.

NB-5853 and NB-5867 inhibition mechanism. In order to better understand the inhibition mechanism of the top-binding nanobodies, a series of competitive ITC

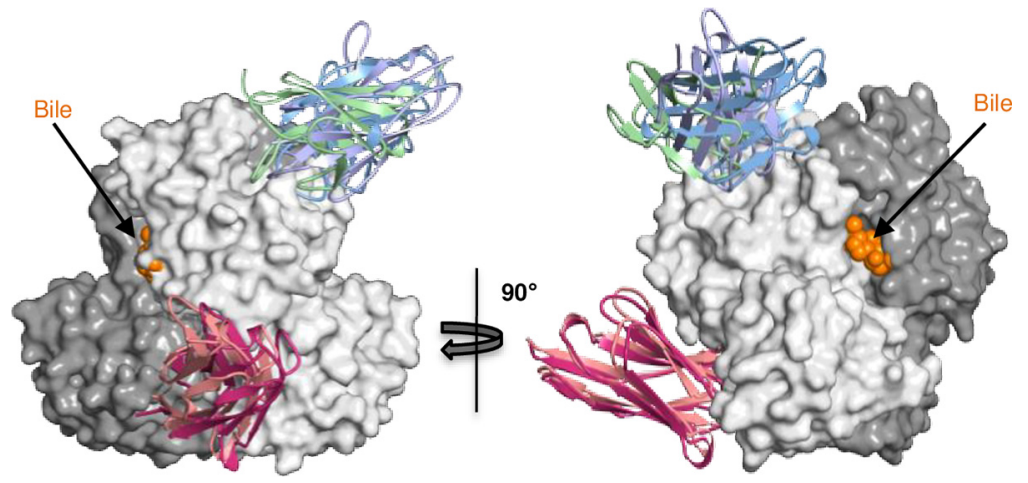

FIG 2 Nanobody binding sites on the P dimer. The X-ray crystal structures of the P domain nanobody complexes were superimposed onto one $\mathrm{P}$ dimer in order to show all four nanobody binding sites. Nanobodies were colored accordingly: NB-5853, sky; NB-5867, purple; NB-5820, salmon; NB-5829, warm pink. NB-5853 and NB-5867 bound on the top of the P2 subdomain, whereas NB-5820 and NB-5829 bound on the side of the P1 subdomain and at a dimeric interface. The structure of the MNV P domain in complex with CD300If (green) receptor and bile acid (orange) were superpositioned onto the $\mathrm{P}$ dimer. 
A
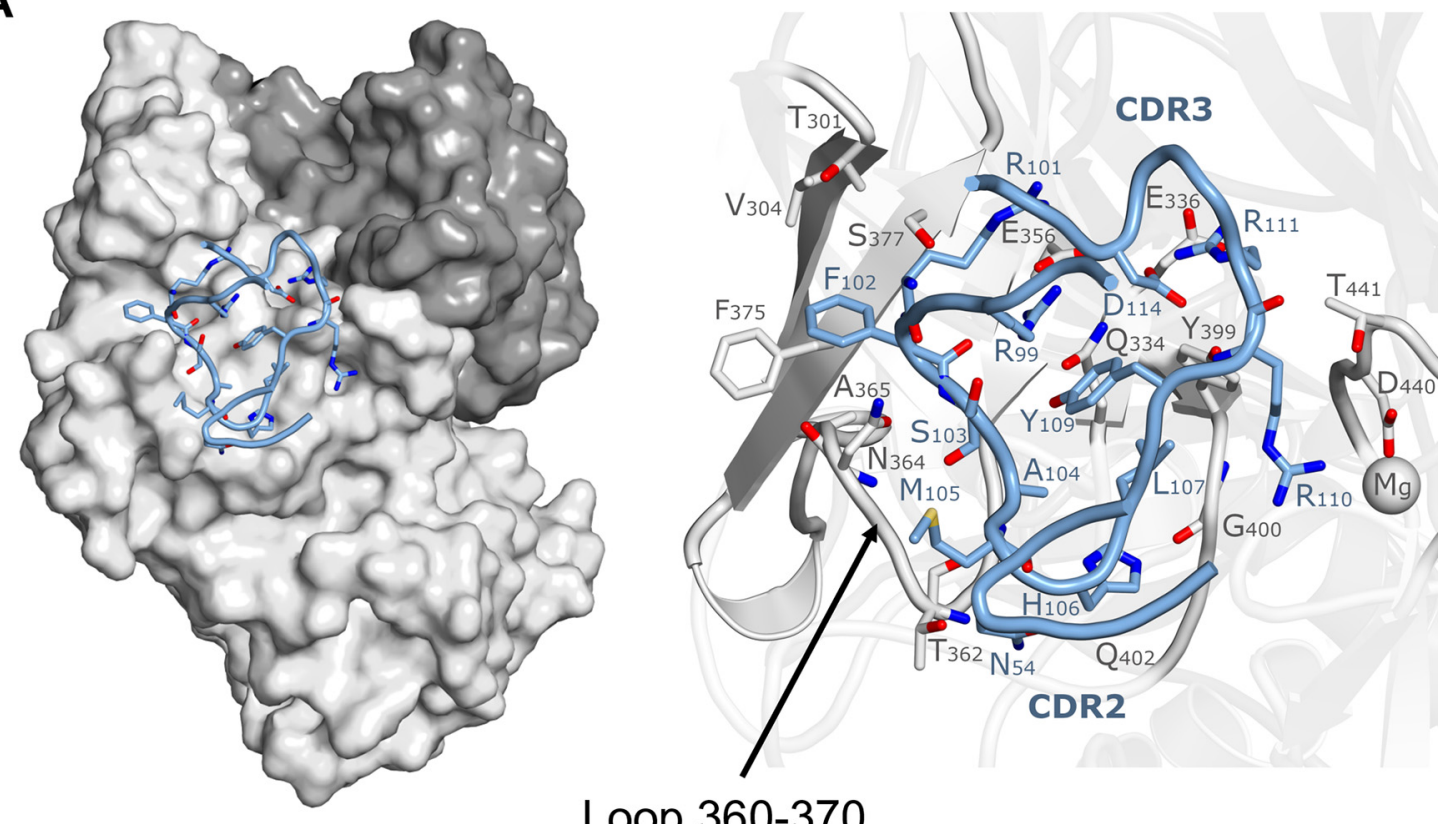

Loop 360-370

B
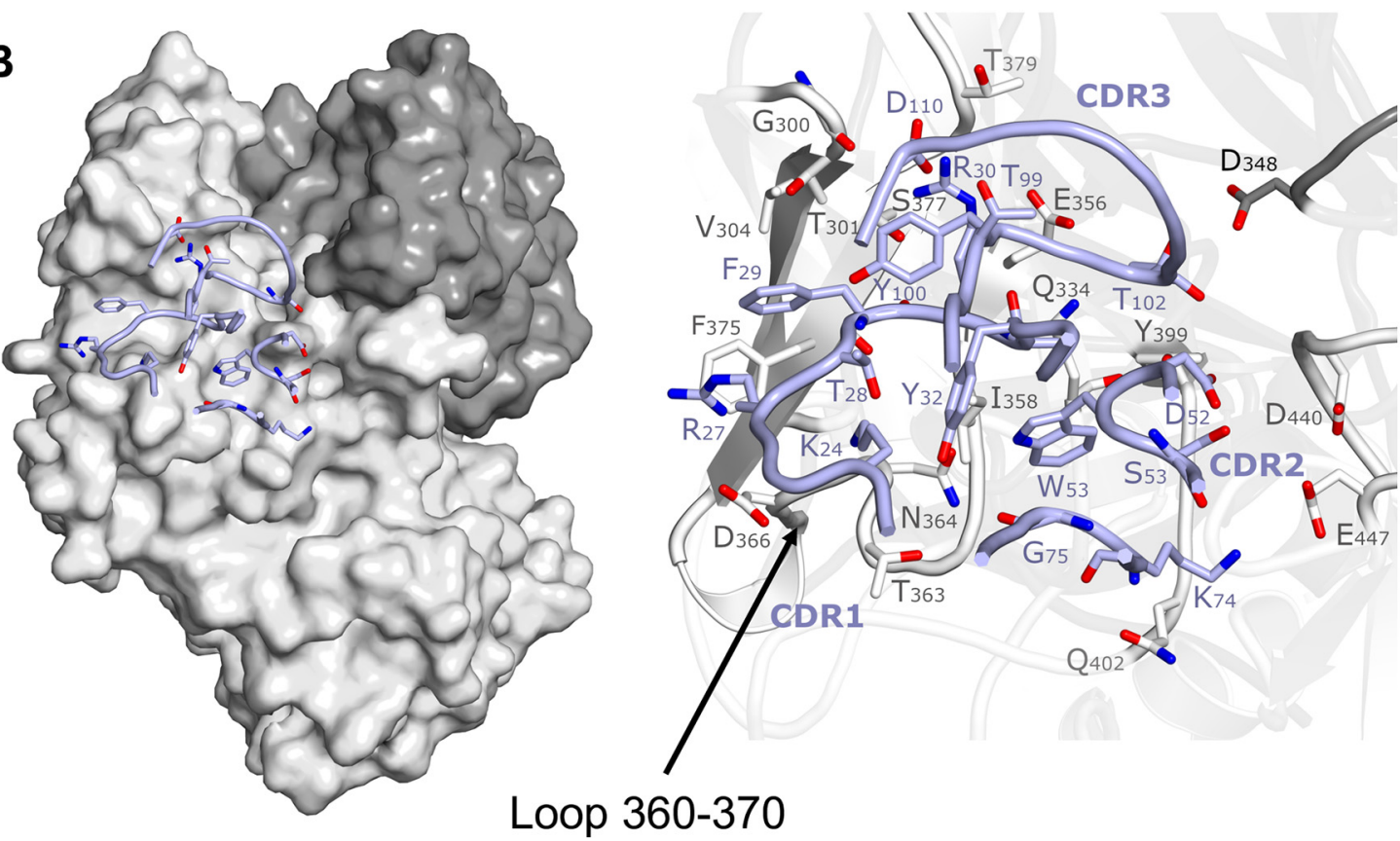

FIG 3 Interaction of the top-binding nanobodies. These nanobodies interacted with one P domain and closely overlapped the CD300If binding site. Hydrogen bond distances were cut at $3.3 \AA$, though the majority were $\sim 2.8 \AA$. (A) NB-5853 was held with a network of $\mathrm{P}$ domain direct hydrogen bonds and hydrophobic interactions (nanobody binding residues shown for simplicity). NB-5853 directly interacted with several P domain residues on the loop 360 to 370 (i.e., T362, N364, and A365). (B) NB-5867 interacted with both P domains, although most bonds were provided by one monomer. NB-5867 also interacted with several $P$ domain residues on the loop 360 to 370 (T363 and N364).

measurements using MNV $P$ domain, the soluble domain of CD300If (sCD300lf), bile acid (glycochenodeoxycholate [GCDCA]), and $\mathrm{CaCl}_{2}$ was performed (Fig. 5A). The binding of NB-5867 to the P domain was not affected by the addition of GCDCA or $\mathrm{CaCl}_{2}$, although the binding affinity in the presence of GCDCA was lower than with $\mathrm{CaCl}_{2}$ and phosphate-buffered saline (PBS) $\left(K_{d}=143 \mathrm{nM}\right.$ versus $K_{d}=14$ and $23 \mathrm{nM}$, respectively). As expected, when the $\mathrm{P}$ domain was preincubated with NB-5867, 

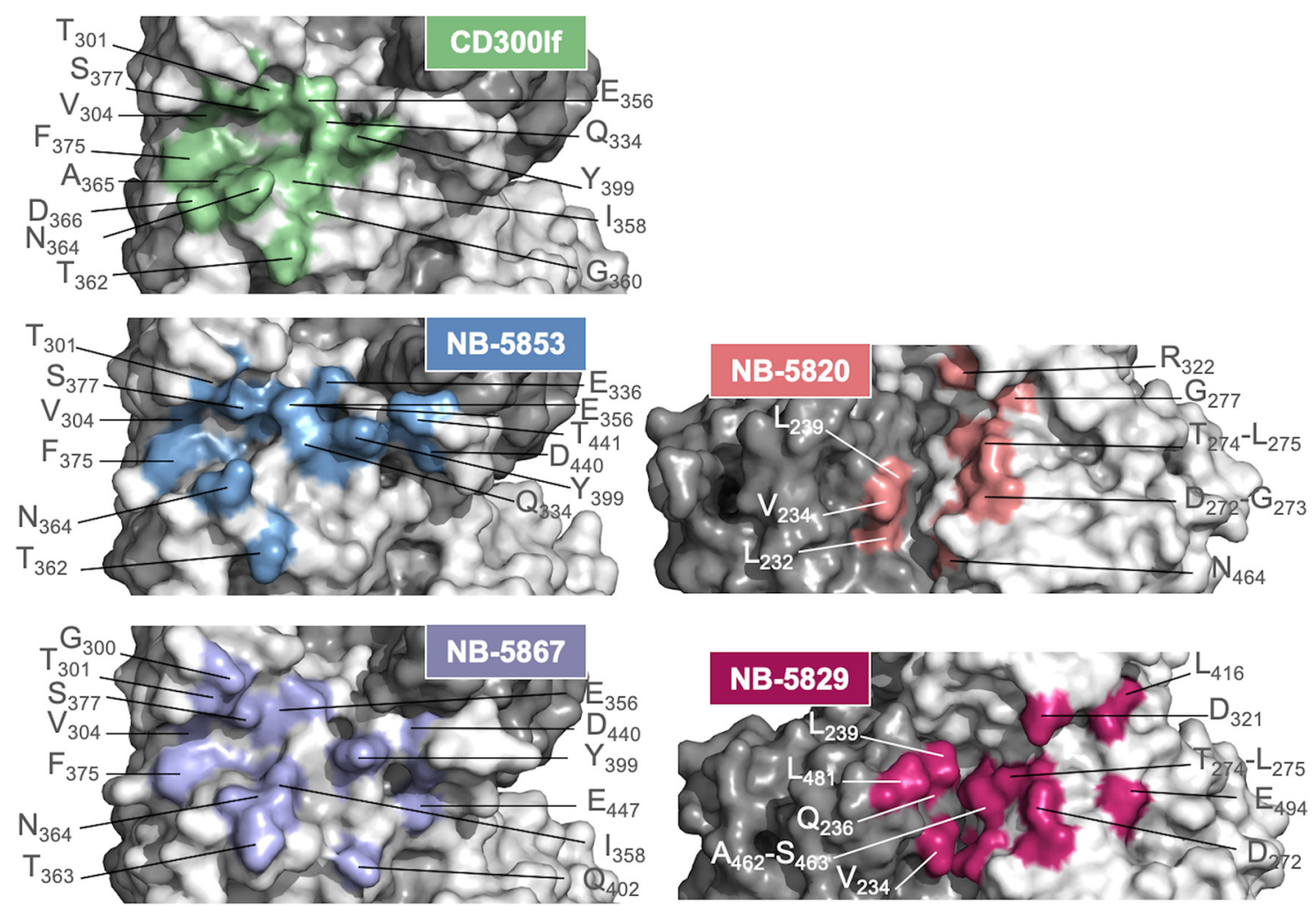

FIG 4 Binding footprints of nanobodies to the P domain. As a comparison, the binding footprints of the receptor CD300lf (green) are shown. NB-5853 (blue) and NB-5867 (purple) exhibit closely overlapping binding footprints with CD300lf. NB-5820 (salmon) and NB-5829 (pink) have epitopes located on the side of the $\mathrm{P}$ domain and interact with both $\mathrm{P}$ domain monomers.

SCD300lf did not bind to the P domain (Fig. 6A). Consequently, the ITC data confirmed the structural findings that these nanobodies blocked the receptor-binding pocket.

In order to further identify other stage(s) of the inhibition, a series of modified entry (postattachment) and postentry assays using the MNV cell culture system were performed (Fig. $6 \mathrm{~B}$ and C). For the entry (postattachment) assay, the virions were first allowed to attach to the cell surface for $3 \mathrm{~h}$ at $4^{\circ} \mathrm{C}$, then unbound virus was removed, and nanobodies were added to the culture medium for $1 \mathrm{~h}$ (viral infection stage). After infection, cells were washed and overlaid with agarose, and the number of plaques was analyzed at $2 \mathrm{dpi}$. For the postentry assay, the nanobodies were only added after MNV infection and were present in agarose overlay until the number of plaques was analyzed. NB-5867 showed strong inhibition in attachment $\left(\mathrm{IC}_{50}=0.02 \mu \mathrm{g} / \mathrm{ml}\right)$ and postentry $\left(\mathrm{IC}_{50}=0.06 \mu \mathrm{g} / \mathrm{ml}\right)$. The inhibition ability was lower in the entry assay $\left(I C_{50}=0.16\right)$. Similar results were obtained for NB-5853. The nanobody showed stronger inhibition in the attachment and postentry assay $\left({ } C_{50}=0.4 \mu \mathrm{g} / \mathrm{ml}\right)$ than in the entry assay $\left(\mathrm{IC}_{50}=0.55 \mu \mathrm{g} / \mathrm{ml}\right)$. Altogether, these cell culture results showed that NB-5867 effectively blocked MNV at the cell attachment stage.

Structure of the MNV P domain and NB-5820 complex. The X-ray crystal structure of the MNV P domain and NB-5820 complex was determined to $1.72-\AA$ r resolution. The $P$ domain interactions were formed between all CDRs and the $C$ terminus of NB-5820 (Fig. 7A). Four P domain residues (V234, Q236, L481, and D272monomer2) formed four direct hydrogen bonds with NB-5820 residues. One P domain residue (Val234) was involved in one hydrophobic interaction with NB-5820. Thirteen water-mediated bonds were also observed. For NB-5820, the P domain loop covering residues 360 to 370 was observed in a comparable position to NB-5853, NB-5867, and CD300lf. Conversely, the loop covering residues 341 to 351 was in a closed position (unlike NB-5853, NB-5867, and CD300lf). 
A

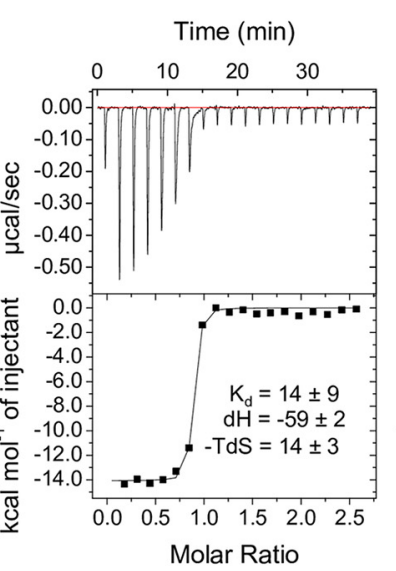

B

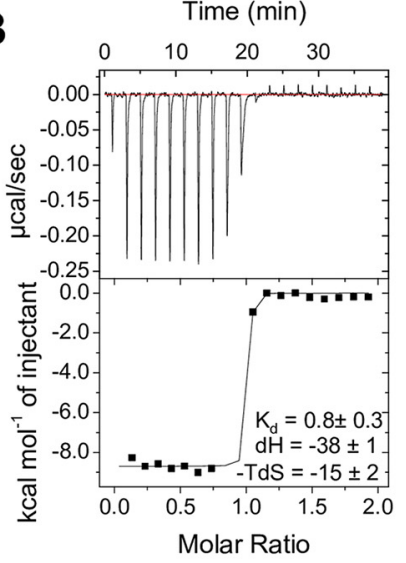

C

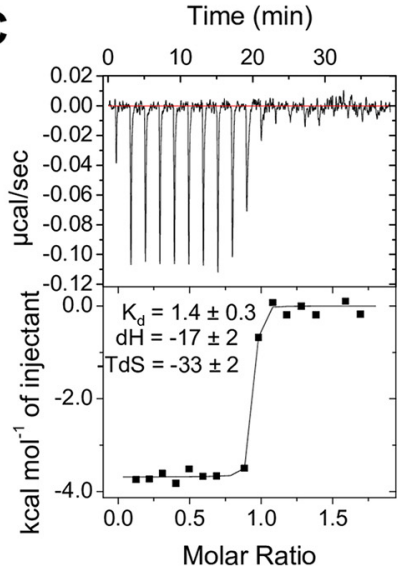

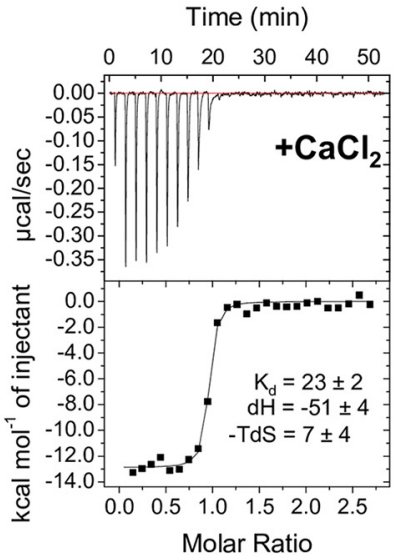
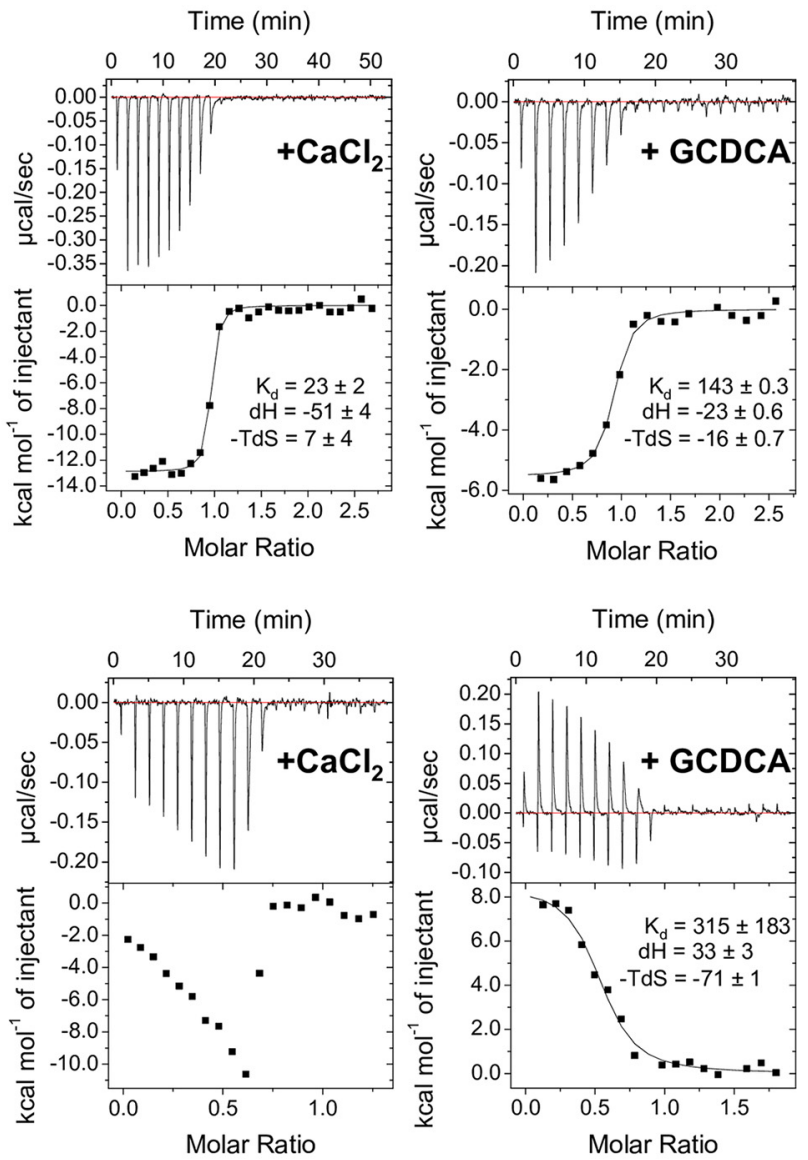

Time (min)

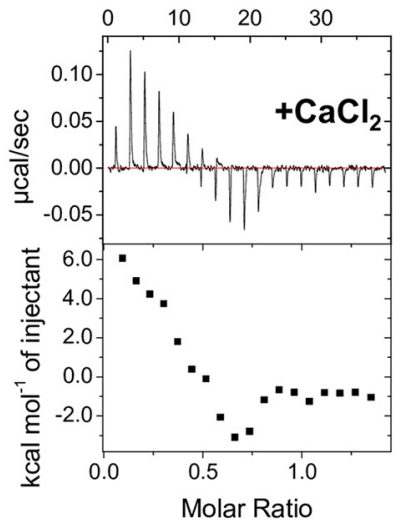

Time (min)

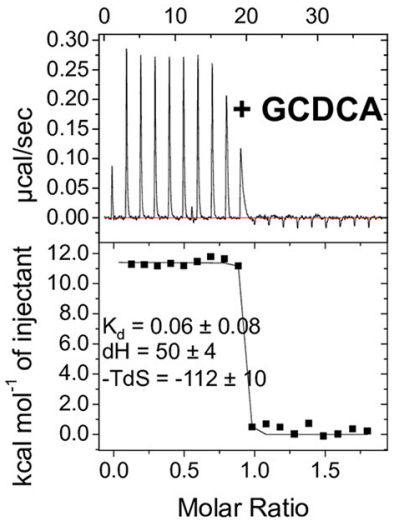

FIG 5 Bile acid and $\mathrm{CaCl}_{2}$ influence on the thermodynamic properties of nanobody binding. Nanobodies were titrated into $\mathrm{P}$ domain in the presence of PBS (control), $5 \mathrm{mM} \mathrm{CaCl}_{2}$, and $50 \mu \mathrm{M} \mathrm{GCDCA}$. Affinity values $\left(K_{d}\right)$ are presented in $n M$, whereas enthalpy $(\mathrm{dH})$ and entropy $(-\mathrm{TdS})$ are measured in $\mathrm{kJ} / \mathrm{mol}$. All experiments were performed twice. (A) NB-5867 binding affinity was not affected by $\mathrm{CaCl}_{2}$ but reduced with GCDCA by 6 to 10 times (from $14 \mathrm{nM}$ to $143 \mathrm{nM}$ ). (B) NB-5820 enthalpy and entropy were both influenced by $\mathrm{CaCl}_{2}$ and $\mathrm{GCDCA}$. For GCDCA, the enthalpy input was reversed from $-38 \mathrm{~kJ} / \mathrm{mol}$ to $33 \mathrm{~kJ} / \mathrm{mol}$, and entropy input changed from -15 $\mathrm{kJ} / \mathrm{mol}$ to $-71 \mathrm{~kJ} / \mathrm{mol}$. (C) NB-5829 properties were similar to NB-5820, where the enthalpy increased ( -17 $\mathrm{kJ} / \mathrm{mol}$ to $50 \mathrm{~kJ} / \mathrm{mol}$ ), and a change in entropy was measured ( $-33 \mathrm{~kJ} / \mathrm{mol}$ to $-112 \mathrm{~kJ} / \mathrm{mol}$ ) when GCDCA was added. For $\mathrm{CaCl}_{2}$, no binding model could be fitted to the data for either NB-5820 or NB-5829.

Interestingly, NB5820 CDR1 and CDR3 interacted with several residues (Val234 and Gln236) located between residues 228 to 250 of the P1 subdomain (Fig. 7A). This stretch of residues contained the hinge region that connected the $\mathrm{S}$ and $\mathrm{P} 1$ subdomains, while Tyr250 aided the binding of bile acid. This initial observation suggested that NB-5820 might influence the hinge region and/or bile acid-binding function(s). 

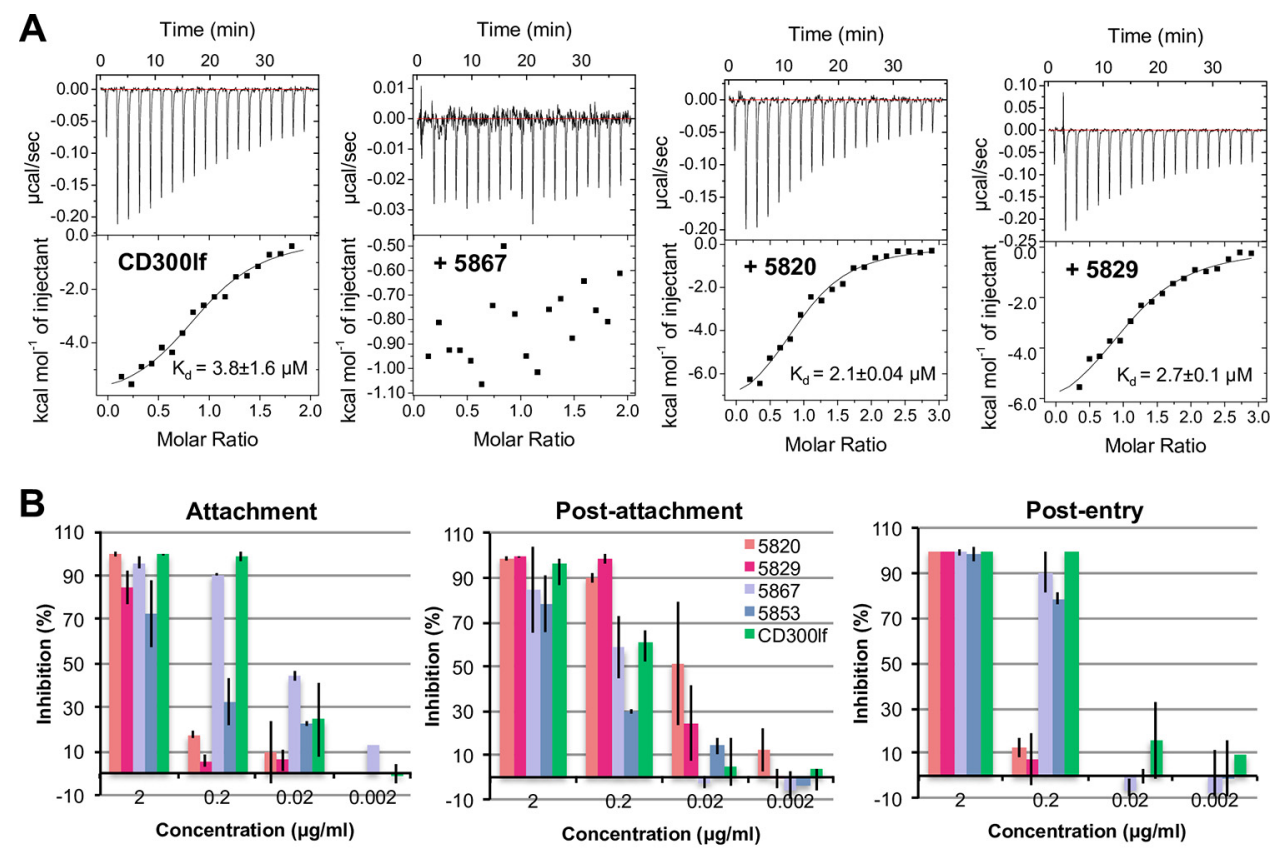

\section{C}

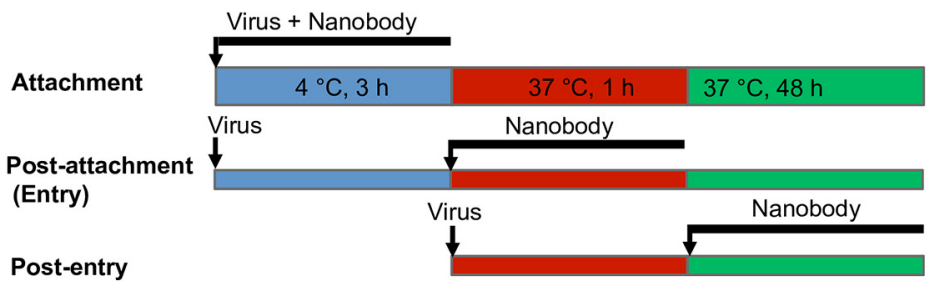

FIG 6 Nanobody competition with sCD300If and functional assays. The ability of nanobodies to complete with CD300lf were analyzed using ITC. (A) sCD300lf was titrated into the $\mathrm{P}$ domain supplemented with $\mathrm{CaCl}_{2}$ and GCDCA. The binding reaction was exothermic with $K_{d}=3.8 \pm 1.6 \mu \mathrm{M}$. Next, the $\mathrm{P}$ domain was premixed with $\mathrm{CaCl}_{2}$, GCDCA, and nanobodies NB-5820, NB-5829, or NB-5867 in a 1:2 molar ratio, followed by sCD300lf titration. NB-5820 and NB-5829 did not change sCD300If binding characteristics, and the affinity with or without nanobody was similar. For NB-5867, no binding signal was observed, which indicated that this nanobody competed with sCD300lf. (B) Nanobody inhibition of MNV infection was analyzed at the attachment, entry, and postentry stages. Nanobodies binding on the top were most effective in the attachment and postentry assays, whereas nanobodies binding at the dimeric interface blocked the entry (postattachment) stage of MNV infection. (C) Schematic representation of the assay methodology. All experiments were performed three times in technical triplicates, and standard deviation is shown.

Structure of MNV P domain and NB-5829 complex with bile acid. Unlike NB-5820, our attempts to produce crystals for the MNV P domain and NB-5829 complex were unsuccessful. However, when bile acid (GCDCA) was added to the complex solution, we obtained crystals that diffracted to $2.15-\AA \AA$ resolution. The complex structure was found to also contain GCDCA and $\mathrm{Mg}^{2+}$. Bile acid formed a number of hydrogen bonds with the $\mathrm{P}$ domain (R390, R392, R437, and W245) as well as hydrophobic interactions (A247, Y250, A290, G314, Q340, Y435, and M436). These binding interactions were almost identical to a previously released MNV $P$ domain GCDCA complex structure $(15,17)$.

NB-5829 bound at the similar P domain dimeric interface as NB-5820 (Fig. 4). However, all three NB-5829 CDRs interacted with the P domain. Also, the total number of interactions was greater than for NB-5820 (Fig. 7B). Eight P domain residues (D272, T274, L275, D313, D321, A462, S463, and E494) formed 10 direct hydrogen bonds with NB-5829 residues. Three P domain residues (I281, L239monomer2, and L481monomer2) were involved in five hydrophobic interactions, and water-mediated bonds provided additional connections between the two proteins.

Another interesting feature of NB-5829 binding was the positions of loops covering residues 341 to 351 and 360 to 370 . For NB-5829, these loops were positioned as 
A
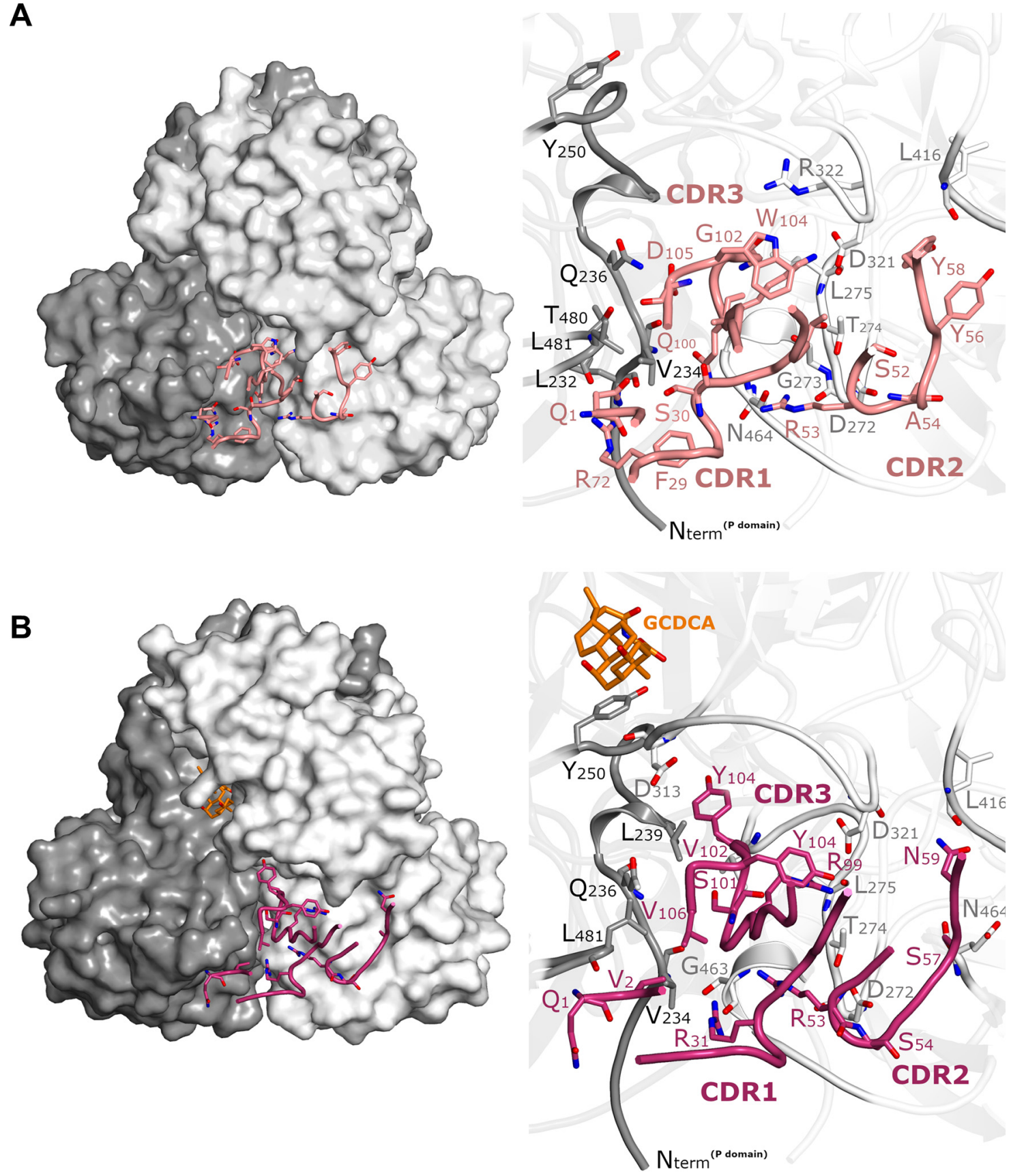

FIG 7 Interaction of the dimeric-binding nanobodies. Both nanobodies bound on the P dimer with a similar footprint. Hydrogen bond distances were cut to $3.3 \AA$. (A) NB-5820 was mostly held with residues from one P domain monomer. (B) Residues from both P domain monomers firmly held NB-5829 with direct hydrogen bonds and hydrophobic interactions.

observed for NB-5853, NB-5867, and CD300If, but dissimilar to NB-5820 that positioned loop 341 to 351 in the closed position (Fig. 7B). This finding suggested that loop 341 to 351 could be opened for bile acid binding but was closed for binding of dimericbinding nanobodies alone. More importantly, NB-5829 interacted with residue L239, which was located close to the hinge region. This finding suggested that NB-5829 and NB-5820 might have similar inhibition mechanisms.

NB-5820 and NB-5829 inhibition mechanism. In previous studies with human norovirus, we showed that a broadly reactive nanobody (Nano-26) bound on the side of the P domain and inhibited VLPs from binding to HBGAs $(27,32,33)$. We discovered that VLP aggregation and disassembly followed when mixed with Nano-26. Surpris- 


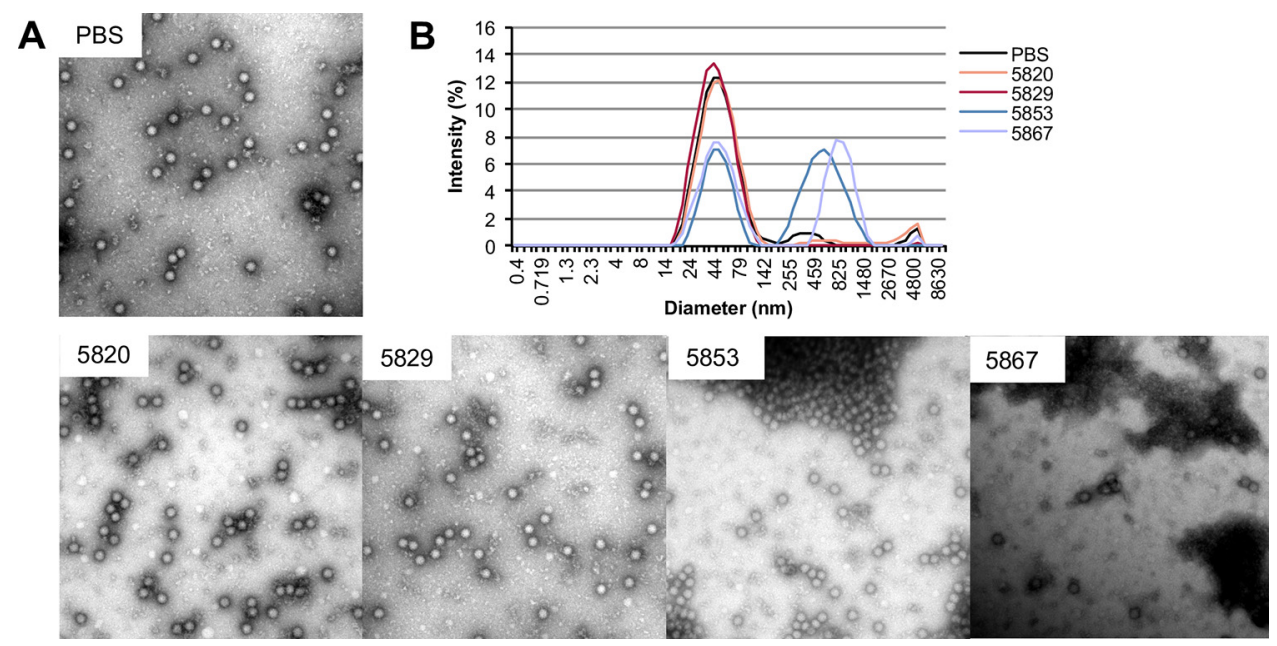

FIG 8 Negative-stain EM and DLS of treated MNV virions. Negative-stain EM (A) and corresponding DLS profiles (B) of untreated and treated MNV virions. Untreated virions were well dispersed and showed little aggregation. After incubation with NB-5820 and NB-5829, the particles appeared as the untreated particles. Incubation with NB-5853 and NB-5867 led to partial aggregation.

ingly, the Nano-26 binding site was remarkably similar to NB-5820 and NB-5829. Thus, we first suspected that NB-5820 and NB-5829 might have similar effects on MNV virions. However, when virions were treated with either these nanobodies, neither disassembly nor particle aggregation occurred (Fig. 8). This finding suggested that NB-5820 and NB-5829 neutralization mechanisms were distinct from Nano-26.

Based on NB-5820 and NB-5829 binding sites, we also assumed that these nanobodies might indirectly interfere with the receptor or cofactor binding functions. Therefore, a series of competitive ITC measurements using MNV P domain, sCD300lf, GCDCA, and $\mathrm{CaCl}_{2}$ were performed. The affinity of MNV P domain binding to sCD300lf $\left(K_{d}=4 \mu \mathrm{M}\right)$ was not affected by the addition of NB-5820 and NB-5829 $\left(K_{d}=2 \mu \mathrm{M}\right.$ and $3 \mu \mathrm{M}$, respectively), indicating that there was no interference with the receptor binding (Fig. 6A). When NB-5829 was titrated into the P domain in the presence of GCDCA, the binding profile changed from exothermic to endothermic, reversing the enthalpy contribution (Fig. 5) and increasing entropy input with a resulting lower $K_{d}$ value of $0.06 \mathrm{nM}$. For the NB-5820, the $K_{d}$ value in the presence of GCDCA was lower than the $P$ domain alone $(315 \mathrm{nM}$ versus $0.8 \mathrm{nM})$. In the presence of $\mathrm{CaCl}_{2}$, the titration curves of NB-5829 and NB-5820 binding to the P domain showed a combination of exothermic and endothermic binding events that could not be fitted to a standard binding model. Based on these findings, our data suggested that bile acid and $\mathrm{CaCl}_{2}$ binding triggered long-distance conformational changes that, in turn, influenced nanobody binding.

Following this result, we performed entry (postattachment) and postentry inhibition assays with NB-5820 and NB-5829 (Fig. 6B and C). We found that NB-5820 and NB-5829 had similar blocking activities in attachment and postentry assays $\left(\mathrm{IC}_{50}=0.5\right.$ to $0.9 \mu \mathrm{g}$ / $\mathrm{ml})$. Surprisingly, the inhibition in the entry assay was $>50$ times higher $\left(\mathrm{IC}_{50}=0.02\right.$ to $0.04 \mu \mathrm{g} / \mathrm{ml}$ ). These data indicated that these nanobodies mainly interfered with a post-receptor-binding stage.

Cryo-EM structure of nanobody binding to MNV virions. We first determined the cryo-electron microscopy (cryo-EM) structure of the apo MNV virion at 4.6- $\AA$ resolution (Fig. 9 and 10A). The virion closely resembled previously solved structures, where the P dimers were raised off the shell by $\sim 15 \AA$ (29). After fitting in the P domain-NB-5829 complex structure into this virion structure, we found that neighboring nanobodies clashed (Fig. 10B). This immediate result suggested that NB-5829 did not initially bind all 180 epitopes or a structural modification was necessary for complete nanobody occupancy.

Next, the cryo-EM structure of the MNV virion-NB-5829 complex was solved to 4.7- $\AA$ resolution (Fig. 9). Similar to the apo virion, the complex virion had $\mathrm{T}=3$ icosahedral 

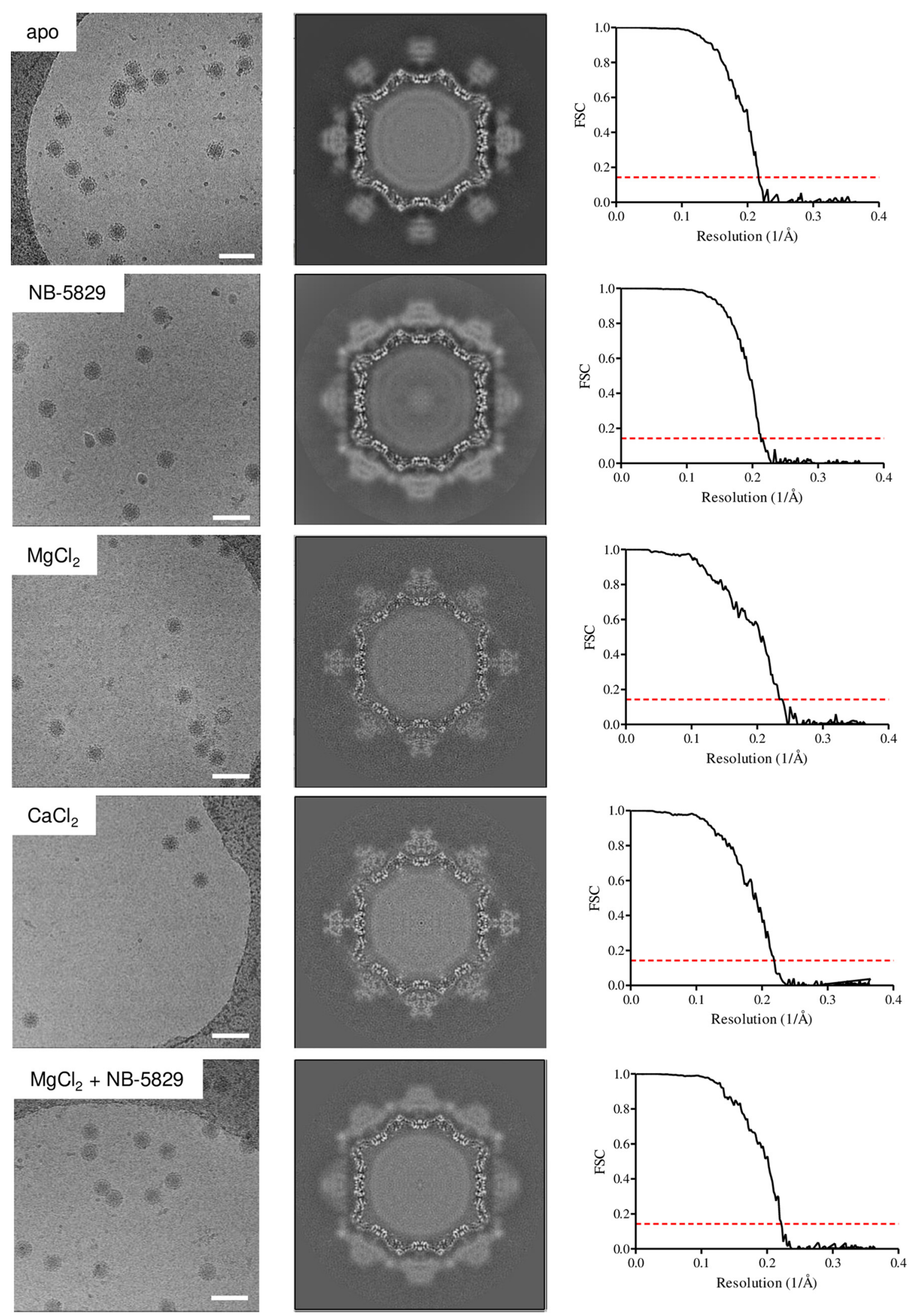

FIG 9 Cryo-EM analysis of virions. Shown are raw micrographs (left column) for apo virion, virion/NB-5829, virion/ $\mathrm{MgCl}_{2}$, virion/CaCl${ }_{2}$, and virion/NB-5829/MgCl 2 . The center column shows the central section of the structure. The FSC curves (right column) indicate resolutions of $4.6 \AA$ for the virion, $4.7 \AA$ for virion/NB-5829, $4.3 \AA$ for virion/ $/ \mathrm{MgCl}_{2}, 4.6 \AA$ for virion/ $/ \mathrm{CaCl}_{2}$, and $4.5 \AA$ for virion/NB-5829/MgCl 2 at an FSC cutoff of 0.143 (red line). Scale bar measures $100 \mathrm{~nm}$. 
A

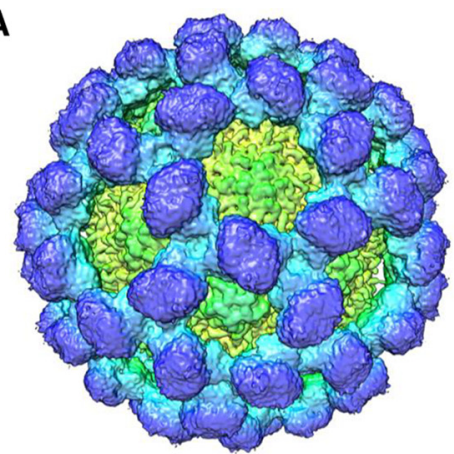

B

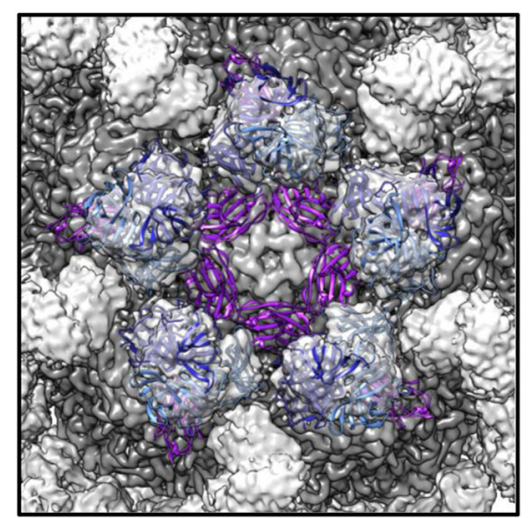

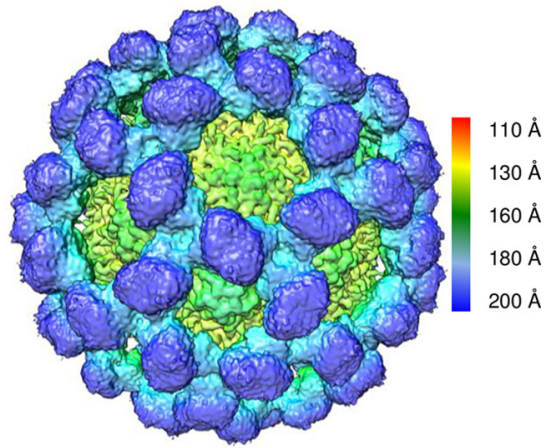

Three-fold axis

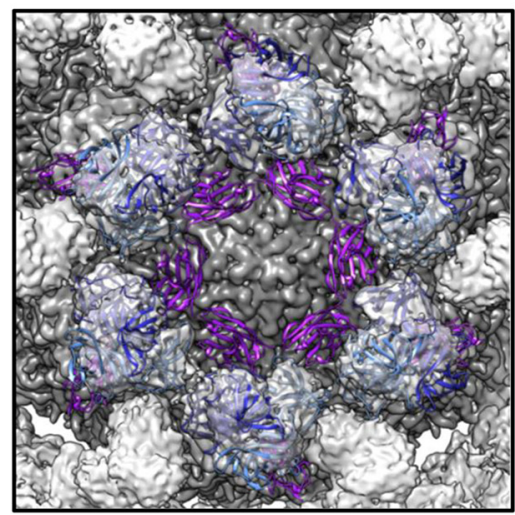

FIG 10 Cryo-EM structure of the apo virion. (A) Stereo view of the apo virion colored by radius. The P dimers (cyan/blue) protruded from the shell (yellow/green). (B) The X-ray crystal structure of the $\mathrm{P}$ domain NB-5829 complex (P domain, blue; NB-5829, purple) was fitted into the apo virion structure. In this model, the nanobodies clashed with adjacent nanobodies at the 3 -fold and 5 -fold icosahedral axes.

symmetry, and the P dimers were raised off the shell (Fig. 11A). This structure showed two additional densities per $\mathrm{P}$ dimer that corresponded to bound nanobodies (Fig. 11B). In this structure, the nanobodies did not clash with neighboring $\mathrm{P}$ dimers or nanobodies. Interestingly, NB-5829 caused the P dimers to rotate $\sim 42^{\circ}$ clockwise. In this orientation, the nanobodies pointed toward the center of the 3- and 5-fold axes. This rotation likely allowed the nanobodies to bind all possible epitopes.

Structural refinement indicated that the $S$ domain was better resolved than the $P$ domain (8-Å resolution versus $4-\AA$ Å resolution, respectively). Therefore, focused reconstruction on the $P$ dimers was performed to resolve the heterogeneity of the $P$ domains. The $\mathrm{P}$ domain and NB-5829 complex structure was fitted into these $\mathrm{P}$ dimers and revealed that the $P$ dimers occupied a variety of tilted positions (Fig. 12A). The $A / B$ dimers were tilted up to $\sim 31^{\circ}$, and the $\mathrm{C} / \mathrm{C}$ dimers were tilted up to $\sim 34^{\circ}$ (Fig. 12B). These results showed that the $\mathrm{P}$ dimers were indeed flexible (in terms of rotation and tilt). Moreover, the dimeric-binding nanobodies forced these major structural changes, which may or may not be structurally detrimental for the virion.

Cryo-EM structure of MNV virions with addition of ions. The ITC data clearly indicated that metal ions and bile acid influenced NB-5829 binding. A recent study showed that the addition of bile acid caused the P dimers to collapse on the shell (34). To better understand this phenomenon with cations, the cryo-EM structures of virions in complex with $\mathrm{Mg}^{2+}$ and $\mathrm{Ca}^{2+}$ were determined to 4.3- and 4.6- $\AA$ - resolution, respectively (Fig. 9). Both structures closely resembled each other, where the $P$ dimers were resting on the shell and rotated $\sim 114^{\circ}$ clockwise (Fig. 13), which was similar to bile salt binding (34). Superposition of the P domain and NB-5829 complex into this cryo-EM structure showed steric clashes between neighboring nanobodies (Fig. 13D). To investigate this further, we incubated virions with NB-5829 and then added $10 \mathrm{mM}$ 
A

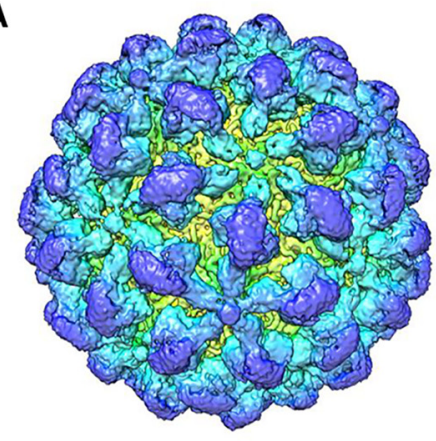

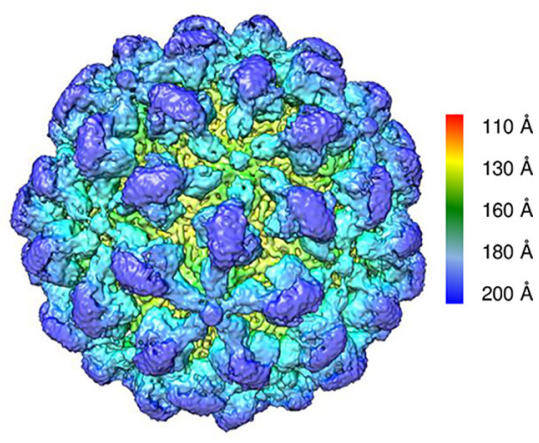

C/C dimer

B

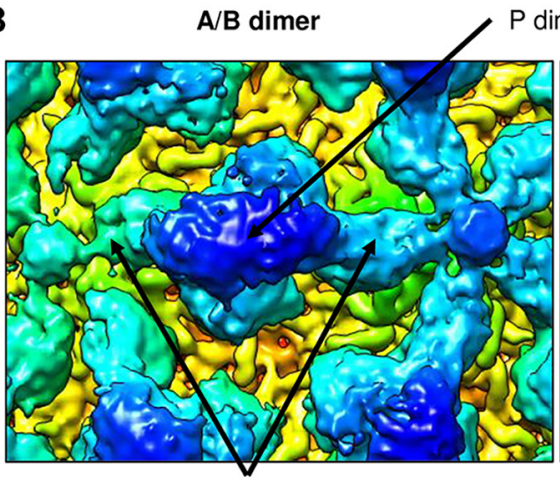

NB-5829

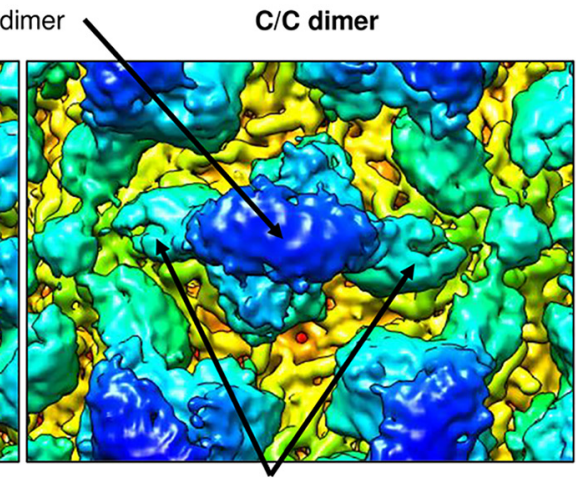

NB-5829

FIG 11 Cryo-EM structure of the MNV virion and NB-5829 complex. Icosahedral reconstruction of the virion and NB-5829 complex was solved to 4.7-Å resolution. (A) Stereo view of the complex structure colored by radius. (B) Closeup view of the complex, where NB-5829 was represented by additional density on the $\mathrm{P}$ domain. In this orientation, where NB-5829 pointed toward the center of the 3- and 5-fold axes, all possible epitopes were occupied.

$\mathrm{MgCl}_{2}$. The cryo-EM structure of this complex was determined to 4.5- $\AA$ resolution (Fig. 9). To our surprise, NB-5829 bound to all $P$ dimers, and these $P$ dimers were raised off the shell, as observed in the cryo-EM virion and NB-5829 complex structure (Fig. 14). This result indicated that NB-5829 could constrain the effects of added cations, and this, in turn, prevented the $\mathrm{P}$ dimers from lowering onto the shell.

\section{DISCUSSION}

Norovirus causes a significant number of infections worldwide, with serious health risks to some individuals, including the elderly and immunocompromised. The U.S. Centers for Disease Control and Prevention estimates that norovirus is the most common cause of acute gastroenteritis in the United States.

The search for norovirus inhibitors is still in its infancy, and there are few reports of antivirals, which are reviewed in reference 35 . Most human norovirus capsid antivirals are targeted toward the HBGA pocket (36-40). In earlier studies, we found several compounds that bind at the HBGA pocket, including human milk oligosaccharides (HMOs) and citrate (41-43). Other studies have discovered MAbs that partially overlap or inhibit the HBGA pocket $(6,28,44-46)$. Importantly, treatment with MAbs has been linked with a decreased risk of infection and illness $(6,28,44-46)$. We have also analyzed human norovirus-specific nanobodies that induce structural modifications and blocked VLP attachment to HBGAs $(27,32,33)$.

In the current study, we provided proof that MNV-specific nanobodies were highly capable of neutralizing MNV in cell culture. The top-binding nanobodies inhibited the receptor-binding site, and this, in turn, blocked particle attachment to cells. Likewise, MAbs A6.2 and 2D3 have an epitope that partially overlaps the receptor site, and these MAbs prevented virion attachment to the receptor $(29,30)$. Our findings showed that NB-5853 and NB-5867 interacted with P domain residues that bound CD300lf. In fact, 

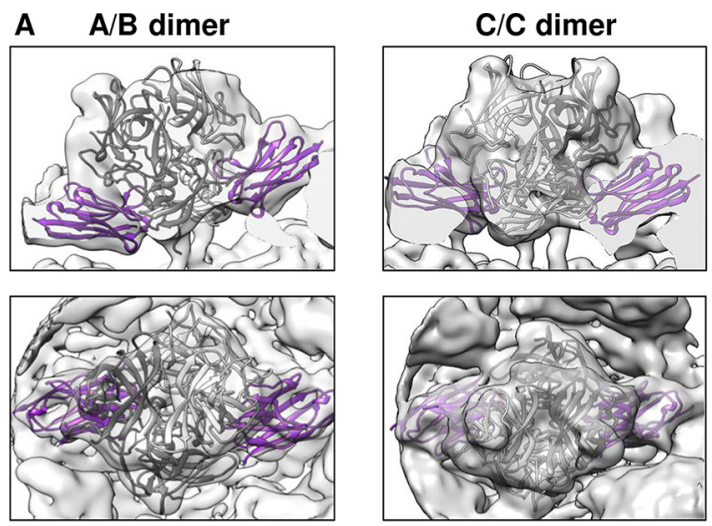

B
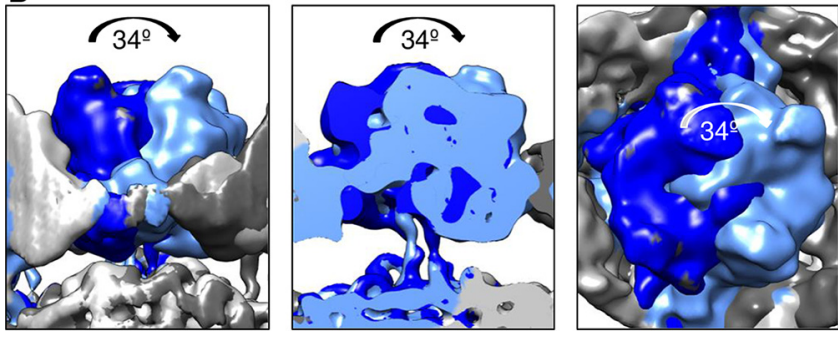

FIG 12 Focused reconstruction of $P$ dimers. (A) Representative class of $A / B$ and $C / C$ dimers after focused reconstruction, fitted with the X-ray crystal structure of the complex (NB-5829, purple; P domain, gray). Side view (top panels) and top view (bottom panels) show that NB-5829 from the X-ray crystal structure fitted well into the model. (B) Focused reconstruction refinement also showed that the P dimers tilted up to $\sim 34^{\circ}$ in $\mathrm{C} / \mathrm{C}$ dimers. A surface representation of the $\mathrm{P}$ domain monomer rotation is shown moving from cyan to blue.

NB-5867 and NB-5853 binding induced several structural modifications that were analogous to CD300lf binding.

The dimeric-binding nanobodies bound to an epitope that connected the $\mathrm{S}$ and $\mathrm{P}$ domains. This binding event likely blocked a structural modification normally associated with cation and bile acid binding. Recently, divalent cations and bile salts were identified as important cofactors of MNV infection and were able to restore infection (17). $\mathrm{Ca}^{2+}$ and $\mathrm{Mg}^{2+}$ ions were required for the CD300lf binding to the MNV capsid protein. Moreover, bile acid binding was proposed to slightly increase the receptorbinding affinity and, in the absence of ions, restore MNV infectivity. Interestingly, bile acid was found to drastically affect the conformation of the MNV particles (34). In an apo state, the MNV P domain is raised $16 \AA \AA$ off the shell (29). In the presence of bile acid, the $\mathrm{P}$ dimers rotated $\sim 90^{\circ}$ and rested on the shell. Our findings showed that cations induced an equivalent structural modification. Importantly, the dimeric-binding nanobodies inhibited this structural rearrangement.

We also found that the addition of bile acid or cations dramatically changed the thermodynamic characteristics of nanobody binding, likely through long-range interactions or solvent rearrangement. Indeed, $\mathrm{Ca}^{2+}$ coordination has been shown to impact the stability and structural flexibility of the polyomavirus SV40, allowing virion structural alterations during early steps of infection (47). Therefore, it is tempting to suggest that similar allosteric and long-distance interactions were responsible for the lowering of the MNV P domain onto the shell, perhaps through altered conformations of the hinge region or additional interactions between $\mathrm{S}$ and $\mathrm{P}$ domains.

Based on these results and previous observations, the following model of MNV entry seems plausible (Fig. 15). In the normal state, MNV virions are in a raised conformation, which can transition to the lowered conformation under the influence of cations or bile. Both raised and lowered conformations might engage the receptor, although the lowered state aids a higher degree of coordination (34). Crucially, the lowered confor- 
A

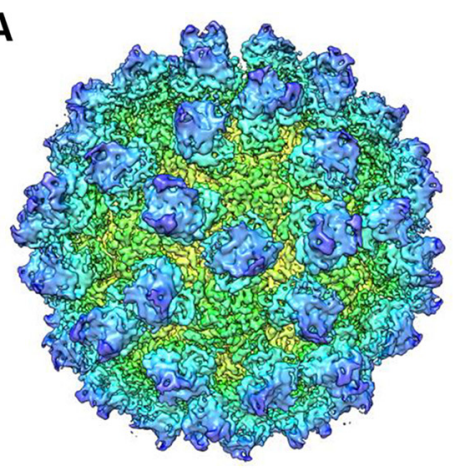

B
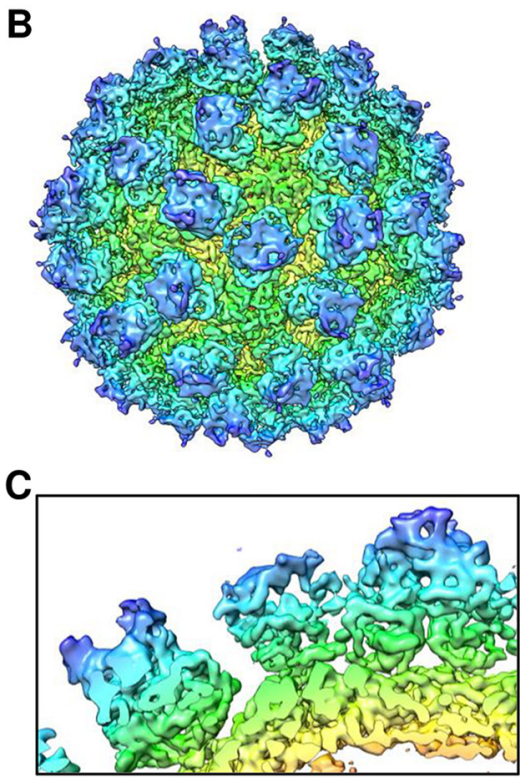

D Five-fold axis

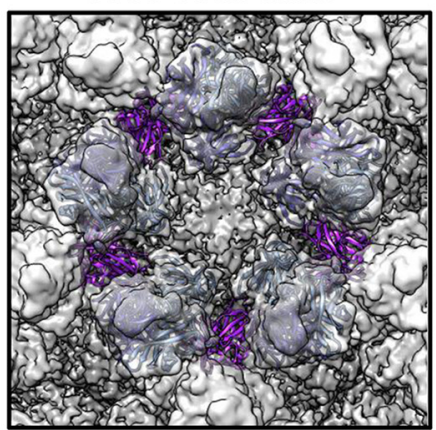

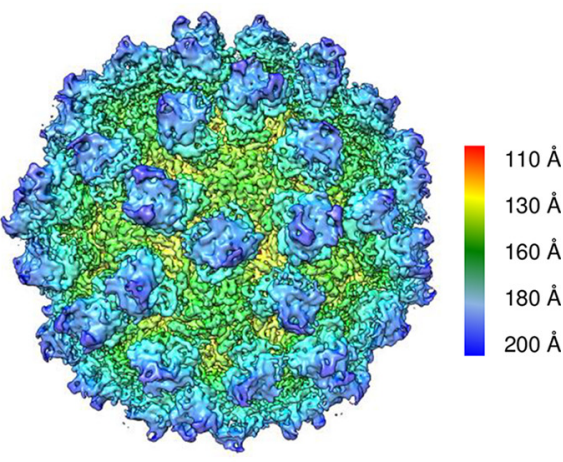
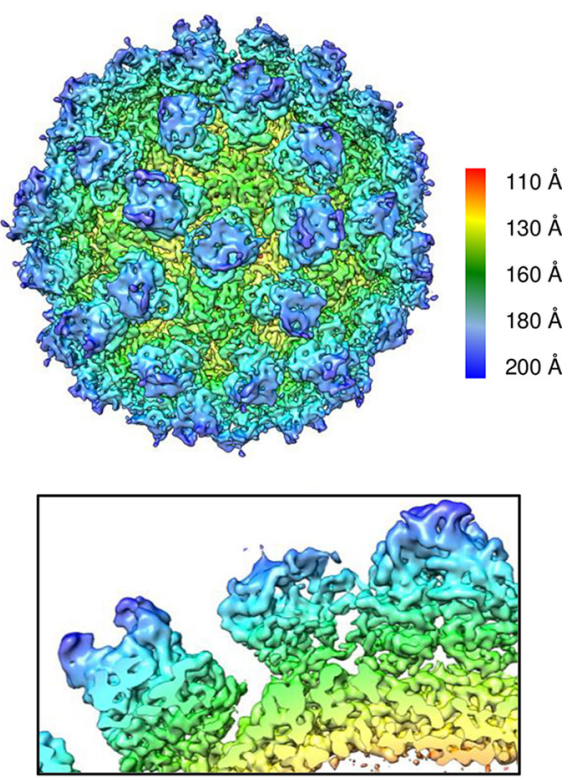

Three-fold axis

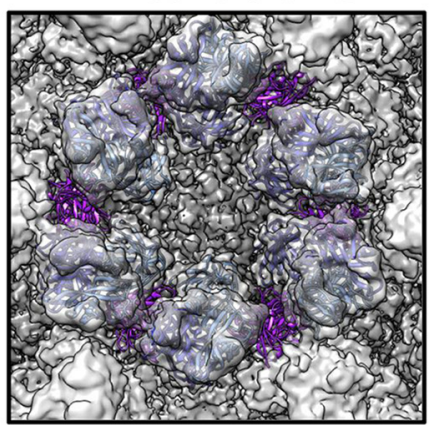

FIG 13 Cryo-EM structures of MNV virion with ions. Icosahedral reconstructions of the virion in with $\mathrm{Mg}^{2+}$ and $\mathrm{Ca}^{2+}$ were determined to 4.3- and 4.6- $\AA$ resolution, respectively. The structures are colored by radius. (A) Stereo view of the virion with $\mathrm{Mg}^{2+}$. The $P$ domains were rotated $\sim 114^{\circ}$ relative to the apo structure. The $\mathrm{P}$ domain was also collapsed on the shell. (B) Stereo view of the virion with $\mathrm{Ca}^{2+}$. (C) Close-up cutaway view of the $\mathrm{S}$ and $\mathrm{P}$ domains (left, virion with $\mathrm{Mg}^{2+}$; right, virion with $\mathrm{Ca}^{2+}$ ) showing the $\mathrm{P}$ dimers resting on the shell. (D) The X-ray crystal structure of the P domain complex with NB-5829 was fitted into the cryo-EM structure of virion $/ \mathrm{Mg}^{2+}$. In this model, the nanobodies clashed with adjacent nanobodies at both 3-fold and 5-fold icosahedral axes.

mation is likely required for subsequent postreceptor attachment steps during cell entry, such as internalization or uncoating. Nanobody binding to a possible conformational switch at the dimeric interface on the side of the $\mathrm{P}$ domain might lock the raised conformation and thereby prevent infection. Similar postbinding antibody inhibition 

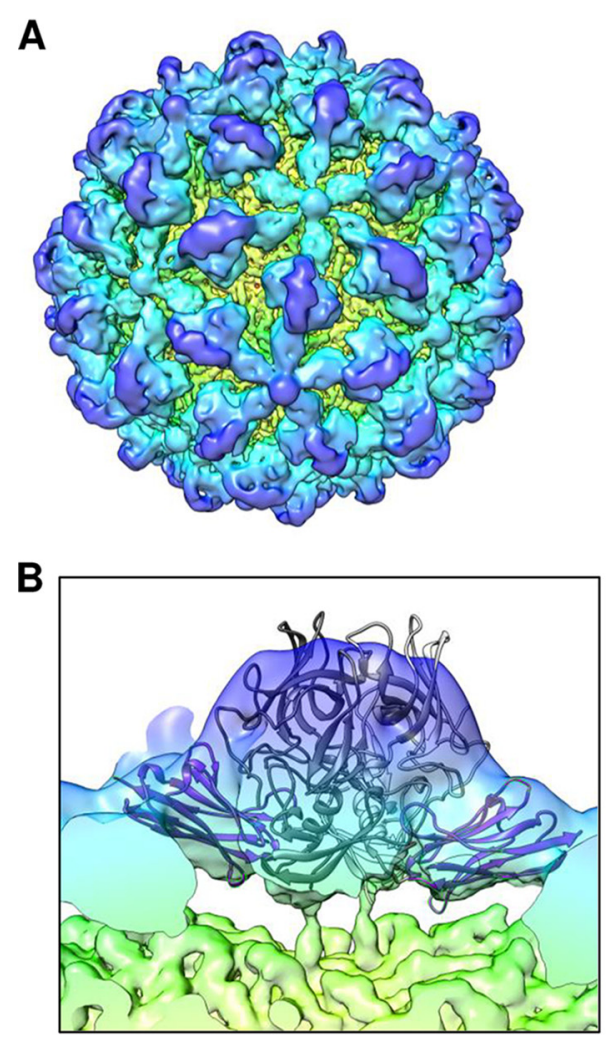
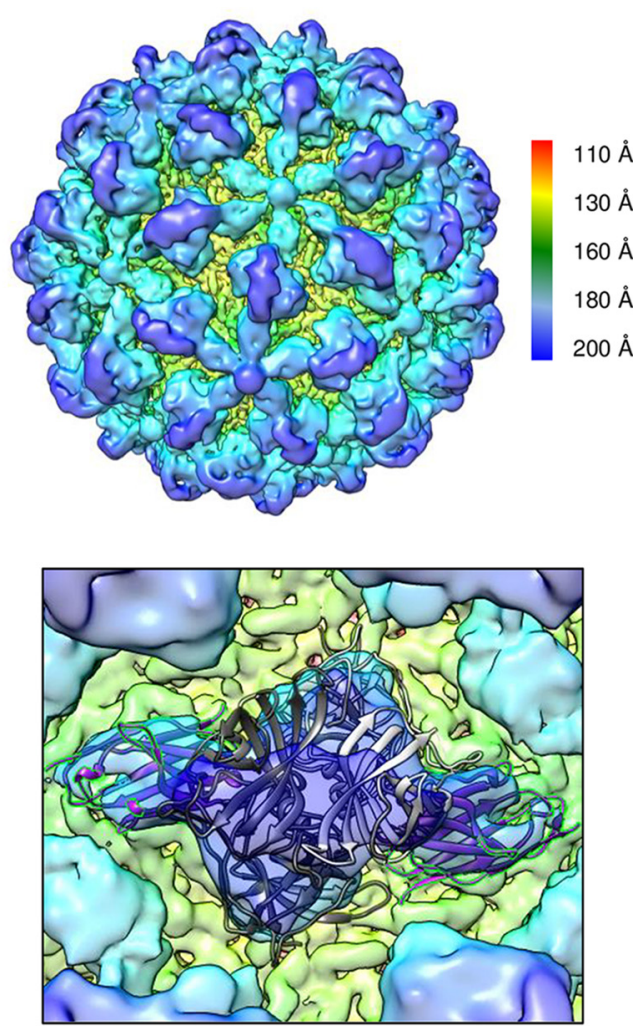

FIG 14 Cryo-EM structure of the MNV virion and NB-5829 complex with $\mathrm{Mg}^{2+}$. Icosahedral reconstruction of this mixture was solved to $4.5-\AA \AA$ resolution. The structure is colored by radius. (A) A stereo view of the virion complex showed extra density for the nanobody. Overall, this structure closely resembled the complex structure of MNV and NB-5829 (i.e., without $\mathrm{Mg}^{2+}$; Fig. 7). (B) A closeup side view (left) and top view (right) showing the fitted crystal structure of MNV with NB-5829. The X-ray crystal structure fitted well into the density, indicating that a comparable structural change as with NB-5829 alone occurred.

mechanisms were described for cytomegalovirus, HIV, respiratory syncytial virus, and chikungunya virus (48-52). For example, uncoating of rhinovirus could be blocked by antiviral WIN compounds that stabilize the capsid by binding to an occluded epitope $(53,54)$.

The raised and lowered $\mathrm{P}$ dimers have also been observed in human noroviruses, and this was thought of as a characteristic feature of different genotypes $(12,14,21)$. Therefore, the question remains open whether this feature is uniquely found in MNV or if bile acid or ions induce the lowering of the $\mathrm{P}$ dimer for human noroviruses as well. In human norovirus cell culture studies, bile acids were shown to improve infection in some genotypes, which suggested its involvement in the infection process (55). In other studies, the addition of bile acid could induce VLP binding to HBGAs for a typical non-HBGA-binder genotype (15). On the other hand, recent studies suggested that the bile acids were not influencing the particles directly but affected intracellular mechanisms that, in turn, enhanced infection (56).

Interestingly, our data showed the striking similarity of vulnerable regions on the human norovirus and MNV. In both cases, binding of the nanobodies to these epitopes alters the normal capsid dynamics and could abort the infection process. In summary, this comprehensive study provided evidence that MNV-specific nanobodies were highly capable of neutralizing MNV, and two different mechanisms of nanobody-based neutralization were described.

\section{MATERIALS AND METHODS}

Protein production. MNV-specific nanobody clones were produced at the VIB nanobody service facility (Belgium) as previously described (33). Briefly, a single alpaca was injected with purified MNV virions (MNV.CW1), and a VH domain of heavy-chain antibodies (VHH) library for MNV-specific nanobod- 


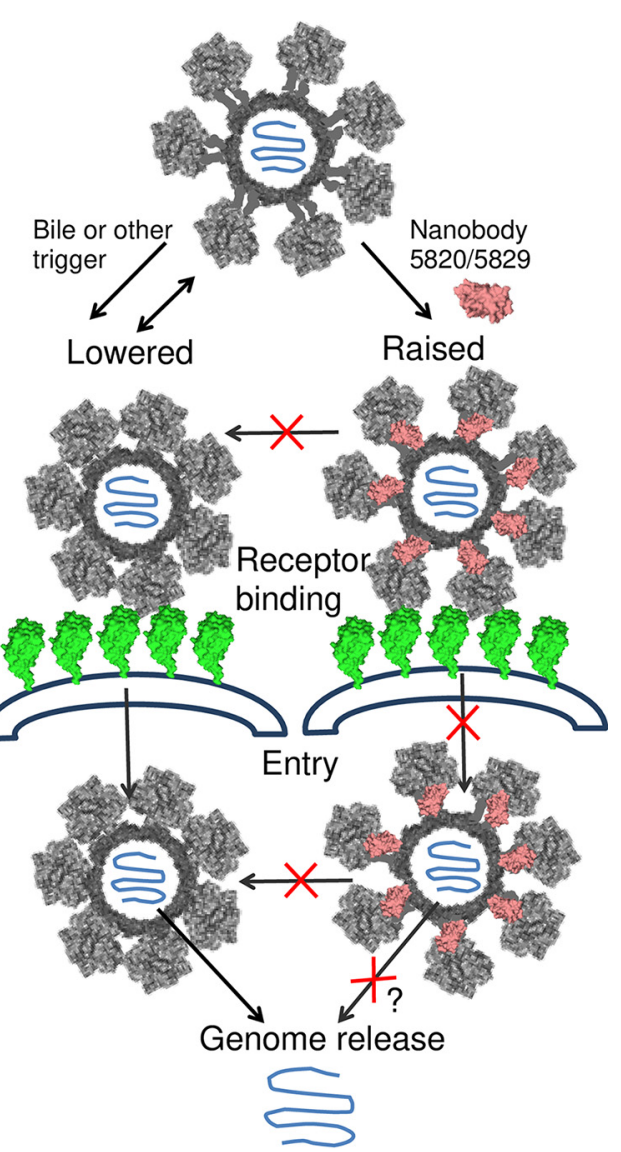

FIG 15 Proposed mechanism of NB-5829 neutralization. In a normal state, the P dimers are raised, which transitions to a lowered conformation under the influence of external or internal triggers. The raised conformation can be locked by NB-5820 and NB-5829. Both raised and lowered states can engage the receptor, CD300lf. However, the lowered state is required for the subsequent postreceptor attachment steps during cell entry. Nanobodies binding to a possible conformational switch on the side of the $P$ domain prevents one or several of these steps.

ies was prepared. A total of 125 nanobody genes were isolated and allocated to 51 distinct families based on CDR sequence diversity. At least one nanobody per family was selected for cloning and expression. The nanobody genes were cloned into the pHEN6C vector, expressed in Escherichia coli WK6 cells, purified using size exclusion chromatography, and stored in phosphate-buffered saline (PBS) or gel filtration buffer (GFB). MNV P domain and the soluble domain of CD300lf (sCD300lf) were produced as described earlier (16).

MNV virion propagation and purification. Murine norovirus (MNV.CW1) was propagated in RAW 264.7 cells as previously described (10). MNV virions were concentrated using ultracentrifugation and then purified using cesium chloride or sucrose ultracentrifugation gradients (29). Fractions were checked by negative-stain electron microscopy (EM). MNV fractions were pooled, concentrated, and dialyzed into PBS.

Electron microscopy and dynamic light scattering. MNV virion morphology was visualized using negative-stain EM as previously described (33). Nanobody and MNV virions were mixed in a 1:1 ratio, incubated for $1 \mathrm{~h}$, and applied on EM grids. Grids were stained with 1\% uranyl acetate and examined on a Zeiss 900 electron microscope (Zeiss, Oberhofen, Germany) at $\times 50,000$ magnification. The hydrodynamic diameters of treated and untreated MNV virions were measured using dynamic light scattering (DLS) on Zetasizer Nano (Malvern Instruments, UK). Samples were diluted 1:50 with PBS up to a final volume of $1 \mathrm{ml}$. We performed 12 measurement runs with standard settings three times (refractive index, 1.331 ; viscosity, 0.89 ; temperature, $25^{\circ} \mathrm{C}$ ). The average result between two independent experiments was calculated.

MNV neutralization assays. The MNV titer was determined with a plaque assay as described previously $(10,16)$. BV2 cells were maintained in Dulbecco modified Eagle medium (DMEM) complete (Life Technologies) supplemented with 10\% fetal bovine serum (FBS; Sigma-Aldrich), $100 \mathrm{U} / \mathrm{ml}$ penicillinstreptomycin (Life Technologies), and $2 \mathrm{mM}$ GlutaMax (Life Technologies) at $37^{\circ} \mathrm{C}$ and $5 \% \mathrm{CO}_{2}$. BV2 cells were seeded in 12-well plates at a concentration of $5 \times 10^{5} \mathrm{cell} / \mathrm{ml}$ and grown overnight at $37^{\circ} \mathrm{C}$ and $5 \%$ $\mathrm{CO}_{2}$ until the start of the assays. Virus neutralization by nanobodies was determined using an attachment plaque assay, an entry plaque assay, and postentry plaque assay (57). MNV-1 CW1 virions were diluted 
in DMEM complete, and equal PFUs $(17,24-26,33,38,42,46,47,56,58)$ were used for all assays. For the attachment assay, MNV was preincubated with various concentrations of nanobodies (diluted in $\mathrm{Ca} / \mathrm{Mg}$ free PBS, 1:9 volume ratio) for $1 \mathrm{~h}$ at room temperature (RT), cooled on ice, and then applied on precooled cell monolayers for $3 \mathrm{~h}$ at $4^{\circ} \mathrm{C}$. Unbound virus was washed twice with ice-cold PBS prior to addition of low-melting-point (LMP) agarose overlay, containing 70\% DMEM, 2.5\% fetal bovine serum (FBS), $15 \mathrm{mM}$ sodium hydrogen carbonate, 5 U penicillin-streptomycin, 25 mM HEPES, 2 mM Glutamax, and $0.35 \%$ low-melting-point agarose. Plates were incubated for 2 days at $37^{\circ} \mathrm{C}$ with $5 \% \mathrm{CO}_{2}$. Cells were fixed by adding $1 \mathrm{ml} /$ well of $4 \%$ formaldehyde directly onto the overlay and incubating for $30 \mathrm{~min}$ at room temperature. Cells were rinsed with water and stained with $0.2 \%$ crystal violet for 15 to $20 \mathrm{~min}$, and plaques were counted. For the entry assay, MNV virions were first allowed to attach to the cell monolayer during incubation for $3 \mathrm{~h}$ at $4^{\circ} \mathrm{C}$. Unbound virus was washed off with ice-cold PBS, and nanobodies serially diluted in DMEM complete (in a 1:9 ratio) were then applied for $1 \mathrm{~h}$ at $37^{\circ} \mathrm{C}$. Plates were washed twice with PBS and covered with an LMP agarose overlay as described above. For the postentry assay, the virus was diluted in DMEM complete to obtain 30 to 40 plaques per well and applied to the cell monolayer for $1 \mathrm{~h}$ at $37^{\circ} \mathrm{C}$. Unbound virus was removed by washing twice with PBS, and agarose overlay containing corresponding nanobody concentrations was applied. The plates were incubated and stained, and plaques were counted as above. The assays were repeated three independent times with technical triplicates to calculate standard deviations. The SCD300If receptor was used as a positive receptor blocking control. The inhibitory activity was calculated related to the PBS buffer alone.

ELISA. Nanobody titers were evaluated using a direct ELISA (41). Briefly, microtiter plates were coated with $\sim 2 \mu \mathrm{g} / \mathrm{ml}$ of MNV virions, washed, and then blocked with skim milk. Nanobodies were first serially diluted, added to the wells, washed, and detected with horseradish peroxidase-conjugated mouse $\alpha$-histidine monoclonal antibody. Absorbance was measured at an optical density of $490 \mathrm{~nm}\left(\mathrm{OD}_{490}\right)$, and all experiments were performed three times in technical triplicates.

Isothermal titration calorimetry measurements. ITC experiments were performed using an ITC200 (Malvern, UK). Samples were dialyzed into the identical PBS buffer and filtered prior to titration experiments. Titrations were performed at $25^{\circ} \mathrm{C}$ by injecting consecutive (1- to 2- $\mu$ l) aliquots of nanobodies $(100$ to $150 \mu \mathrm{M})$ into the MNV P domain $(10$ to $20 \mu \mathrm{M})$ in 120-s intervals. The binding data were corrected for the heat of dilution and fitted to a one-site binding model. Three runs per nanobody were performed, and average $K_{d}, \mathrm{dS}$, and enthalpy $(\mathrm{dH})$ values were calculated. For the ITC measurements with bile acid and calcium, the P domain was premixed with $50 \mu \mathrm{M} \mathrm{GCDCA}$ or $5 \mathrm{mM} \mathrm{CaCl} \mathrm{C}_{2}$. Titrations with nanobodies were then performed as described above. For competitive ITC experiments, $200 \mu \mathrm{M}$ sCD300lf was titrated into the MNV P domain premixed with GCDCA and $\mathrm{CaCl}_{2}$. The sample cell contents were then used for the subsequent titration with nanobody. For the measurements with bile, $100 \mu \mathrm{M} \mathrm{GCDCA}$ was mixed with the MNV virion, and then nanobodies were titrated as described above. All experiments were performed twice.

P domain and nanobody complex purification and crystallization. For each complex, the MNV (CW3) P domain and nanobody were mixed in a 1:1.5 molar ratio and incubated overnight at $4^{\circ} \mathrm{C}$. The complex was purified by size exclusion chromatography using a Superdex 200 column, and the peak shift observed in the ultraviolet elution profile clearly indicated the presence of the $\mathrm{P}$ domain/nanobody complex in solution. The mixture was then concentrated to $\sim 4$ to $6 \mathrm{mg} / \mathrm{ml}$. When required for the structural study, $100 \mu \mathrm{M}$ bile acid (GCDCA) and $100 \mu \mathrm{M} \mathrm{Mg}{ }^{2+}$ were added at this stage to the concentrated mixture. Crystallization conditions were screened using the sitting-drop vapor diffusion method and optimized using the hanging-drop method. P domain NB-5820: $0.1 \mathrm{M}$ Tris (pH 8.5) and 25\% polyethylene glycol (PEG) 3000; P domain NB-5829: $0.1 \mathrm{M}$ phosphate-citrate ( $\mathrm{pH} 4.2$ ), $0.2 \mathrm{M}$ sodium chloride, and 20\% PEG 8000; P domain NB-5853: $0.1 \mathrm{M}$ sodium acetate ( $\mathrm{pH}$ 4.5), $0.2 \mathrm{M}$ lithium sulfate, and 30\% PEG 8000; and P domain NB-5867: $0.1 \mathrm{M}$ citrate (pH 5.0) and 20\% PEG 6000. Crystals were soaked in a cryoprotectant solution containing the same mother liquor with an addition of 30\% 1,2-ethandiol and then flash frozen at $100 \mathrm{~K}$.

Data collection, structure solution, and refinement. X-ray diffraction data were collected at the European Synchrotron Radiation Facility, France, at beamlines ID29, ID30A-3, and ID30B, and processed with XDS (59). The structures were solved by molecular replacement in Phaser-MR (58) using the monomeric structure of the previously solved murine norovirus $\mathrm{P}$ domain (PDB accession no. 3LQ6). Alternate cycles of manual model rebuilding with Coot (60) and refinement with the REFMAC5 (CCP4 program suite) $(61,62)$ were used. Final structures have been validated with MolProbity $(63)$ and the wwPDB validation server (https://validate.wwpdb.org).

Cryo-EM of MNV virions. Purified MNV CW1 virions $(1 \mathrm{mg} / \mathrm{ml})$ were diluted in PBS. These were loaded onto freshly glow-discharged Quantifoil 0.6/1 grids and vitrified using a Mark IV Vitrobot, held at $12^{\circ} \mathrm{C}$ and $100 \%$ humidity. After blotting the samples for $20 \mathrm{~s}$, the samples were plunge frozen in liquid ethane and stored in liquid nitrogen. Data collection was performed on a Titan Krios operated at $300 \mathrm{keV}$ and equipped with a K3 direct electron detector. Movies were collected at $\times 64,000$ magnification, corresponding to a pixel size of $1,368 \AA \AA$ pixel (px). The movies, each containing 15 frames, were corrected for drift using MotionCor2 (64), and defocus estimation was done with CTFFIND4.1 (58), as implemented in Relion 3 (65). All further processing steps were performed in Relion 3. Apo particles were picked automatically from 1,588 micrographs. Following two-dimensional and three-dimensional classification, a subset of 21,424 particles was used for icosahedral reconstruction, leading to a resolution of $4.6 \AA$, as determined using Fourier shell correlation (FSC) with a cutoff at 0.143.

Cryo-EM of virion and NB-5829 complex. MNV CW1 virions $(1 \mathrm{mg} / \mathrm{ml})$ were incubated with NB-5829 $(1 \mathrm{mg} / \mathrm{ml})$ for $30 \mathrm{~min}$ at RT before vitrification. Particles were prepared and processed as 
described above. For this complex, 32,612 particles were picked from 3,599 micrographs. Refinement of the particles resulted in a structure at $4.7-\AA \AA$ resolution (FSC cutoff at 0.143 ). Focused reconstruction of this complex was also performed as described earlier (66). Briefly, the symmetry of the data set was expanded following icosahedral refinement so that each particle was assigned 60 orientations that were matching the repeated views of the icosahedral particle. With this expanded data set, three-dimensional classification without orientation refinement was done to resolve the asymmetric differences within the single VP1 dimers. To include only the VP1 dimers in the classification, a cylindrical mask was prepared in SPIDER (67) and positioned in UCSF Chimera (60) to only include the single capsomers.

Cryo-EM of virion and cation complexes. MNV CW1 virions $(1 \mathrm{mg} / \mathrm{ml})$ were incubated with $10 \mathrm{mM}$ $\mathrm{MgCl}_{2}$ or $\mathrm{CaCl}_{2}$ prior to vitrification. Particles were prepared and processed as described above. For MNV and $\mathrm{Mg}^{2+}, 2,783$ particles from 611 micrographs were used for final reconstruction and resulted in a resolution of $4.3 \AA$ (FSC cutoff at 0.143 ). For $\mathrm{MNV}$ and $\mathrm{Ca}^{2+}, 2,637$ particles were picked from 303 micrographs that led to a final resolution of $4.6 \AA$ (FSC cutoff at 0.143 ). For the complex of MNV/NB-5829/Mg ${ }^{2+}$, the virions were first incubated with NB-5829 for 30 min at RT and then $10 \mathrm{mM}$ $\mathrm{MgCl}_{2}$ for $3 \mathrm{~h}$ at RT. A total of 7,386 particles from 293 micrographs revealed a structure of $4.5 \AA$ (FSC cutoff at 0.143 ).

Data availability. Coordinates of the final MNV crystal structures have been deposited in the Protein Data Bank (PDB) under the following accession numbers: $P$ domain in complex with NB-5853, 6XW6; P domain in complex with NB-5867, 6XW4; P domain in complex with NB-5820, 6XW5; and P domain in complex with NB-5829, 6XW7.

The cryo-EM structure of the MNV capsid was deposited in the Electron Microscopy Data Bank (EMDB) (accession no. EMD-10596). The density of the virion and NB-5829 complex was deposited in the EMDB under accession no. EMD-10597. Structures of the MNV virion and cation complexes have been deposited in the EMDB as EMD-10598 (MNV with $\mathrm{Mg}^{2+}$ ), EMD-10599 (MNV in complex with $\mathrm{Ca}^{2+}$ ), and EMD-10600 (MNV with NB-5829 and $\mathrm{Mg}^{2+}$ ).

\section{ACKNOWLEDGMENTS}

We thank David Bhella and Götz Hofhaus for assistance with cryo-EM data collection and structural refinements and Benedikt Wimmer for setting up the cryo-EM software. We are grateful to Skip Virgin for the MNV virions. We acknowledge the excellence cluster CellNetworks (cryo-EM network) of the University of Heidelberg for cryo-EM data collection, the EM core facility at DKFZ, Baden-Württemberg High Performance Cluster (bwHPC), and the data storage service SDS@hd. We are grateful to the Protein Crystallization Platform facility of BZH-Heidelberg University. We also thank the European Synchrotron Radiation Facility and staff (France) for the use of and help at beamlines ID29, ID30A-3, and ID30B.

The funding for this study was provided by the CHS Foundation, the BadenWürttemberg Stiftung (glycan-based antiviral agents), and the BMBF VIP+ (Federal Ministry of Education and Research) (NATION, 03VP00912).

\section{REFERENCES}

1. King A, Lefkowitz E, Adams MJ, Carstens EB (ed). 2011. Virus taxonomy: ninth report of the International Committee on Taxonomy of Viruses, 1 st ed. Elsevier, London, United Kingdom.

2. Green KY. 2013. Caliciviridae: the noroviruses, p 582-608. In Knipe DM, Howley PM, Cohen Jl, Griffin DE, Lamb RA, Martin MA, Roizman B (ed), Fields virology, 6th ed. Lippincott Williams \& Wilkins, Philadelphia, PA.

3. Gastañaduy PA, Hall AJ, Curns AT, Parashar UD, Lopman BA. 2013. Burden of norovirus gastroenteritis in the ambulatory setting - United States, 2001-2009. J Infect Dis 207:1058-1065. https://doi.org/10.1093/ infdis/jis942.

4. Hall AJ, Lopman BA, Payne DC, Patel MM, Gastañaduy PA, Vinjé J, Parashar UD. 2013. Norovirus disease in the United States. Emerg Infect Dis 19:1198-1205. https://doi.org/10.3201/eid1908.130465.

5. Koo HL, Neill FH, Estes MK, Munoz FM, Cameron A, Dupont HL, Atmar RL. 2013. Noroviruses: the most common pediatric viral enteric pathogen at a large university hospital after introduction of rotavirus vaccination. J Pediatric Infect Dis Soc 2:57-60. https://doi.org/10.1093/jpids/pis070.

6. Atmar RL, Bernstein DI, Harro CD, Al-Ibrahim MS, Chen WH, Ferreira J, Estes MK, Graham DY, Opekun AR, Richardson C, Mendelman PM. 2011. Norovirus vaccine against experimental human Norwalk virus illness. $\mathrm{N}$ Engl J Med 365:2178-2187. https://doi.org/10.1056/NEJMoa1101245.

7. Bernstein DI, Atmar RL, Lyon GM, Treanor JJ, Chen WH, Jiang X, Vinje J, Gregoricus N, Frenck RW, Jr, Moe CL, Al-Ibrahim MS, Barrett J, Ferreira J, Estes MK, Graham DY, Goodwin R, Borkowski A, Clemens R, Mendelman
PM. 2015. Norovirus vaccine against experimental human Gll.4 virus illness: a challenge study in healthy adults. J Infect Dis 211:870-878. https://doi.org/10.1093/infdis/jiu497.

8. Ramirez K, Wahid R, Richardson C, Bargatze RF, El-Kamary SS, Sztein MB, Pasetti MF. 2012. Intranasal vaccination with an adjuvanted Norwalk virus-like particle vaccine elicits antigen-specific $B$ memory responses in human adult volunteers. Clin Immunol 144:98-108. https://doi.org/10 .1016/j.clim.2012.05.006.

9. Ward JM, Wobus CE, Thackray LB, Erexson CR, Faucette LJ, Belliot G, Barron EL, Sosnovtsev SV, Green KY. 2006. Pathology of immunodeficient mice with naturally occurring murine norovirus infection. Toxicol Pathol 34:708-715. https://doi.org/10.1080/01926230600918876.

10. Wobus CE, Karst SM, Thackray LB, Chang KO, Sosnovtsev SV, Belliot G, Krug A, Mackenzie JM, Green KY, Virgin HW. 2004. Replication of Norovirus in cell culture reveals a tropism for dendritic cells and macrophages. PLoS Biol 2:e432. https://doi.org/10.1371/journal.pbio.0020432.

11. Wobus CE, Thackray LB, Virgin HW, IV. 2006. Murine norovirus: a model system to study norovirus biology and pathogenesis. J Virol 80: 5104-5112. https://doi.org/10.1128/JVI.02346-05.

12. Prasad BV, Hardy ME, Dokland T, Bella J, Rossmann MG, Estes MK. 1999. X-ray crystallographic structure of the Norwalk virus capsid. Science 286:287-290. https://doi.org/10.1126/science.286.5438.287.

13. Haga K, Fujimoto A, Takai-Todaka R, Miki M, Doan YH, Murakami K, Yokoyama M, Murata K, Nakanishi A, Katayama K. 2016. Functional 
receptor molecules CD300lf and CD300ld within the $\mathrm{CD} 300$ family enable murine noroviruses to infect cells. Proc Natl Acad Sci U S A 113:E6248-E6255. https://doi.org/10.1073/pnas.1605575113.

14. Jung J, Grant T, Thomas DR, Diehnelt CW, Grigorieff N, Joshua-Tor L. 2019. High-resolution cryo-EM structures of outbreak strain human norovirus shells reveal size variations. Proc Natl Acad Sci U S A 116: 12828-12832. https://doi.org/10.1073/pnas.1903562116.

15. Kilic T, Koromyslova A, Hansman GS. 2018. Structural basis for human norovirus capsid binding to bile acids. J Virol 93:e01581-18. https://doi .org/10.1128/JVI.01581-18.

16. Kilic T, Koromyslova A, Malak V, Hansman GS. 2018. Atomic structure of the murine norovirus protruding domain and soluble CD300lf receptor complex. J Virol 92:e00413-18. https://doi.org/10.1128/JVI.00413-18.

17. Nelson CA, Wilen CB, Dai Y-N, Orchard RC, Kim AS, Stegeman RA, Hsieh LL, Smith TJ, Virgin HW, Fremont DH. 2018. Structural basis for murine norovirus engagement of bile acids and the CD300lf receptor. Proc Natl Acad Sci U S A 115:E9201-E9210. https://doi.org/10.1073/pnas .1805797115 .

18. Orchard RC, Wilen CB, Doench JG, Baldridge MT, McCune BT, Lee YC, Lee S, Pruett-Miller SM, Nelson CA, Fremont DH, Virgin HW. 2016. Discovery of a proteinaceous cellular receptor for a norovirus. Science 353: 933-936. https://doi.org/10.1126/science.aaf1220.

19. Tan M, Hegde RS, Jiang X. 2004. The $P$ domain of norovirus capsid protein forms dimer and binds to histo-blood group antigen receptors. J Virol 78:6233-6242. https://doi.org/10.1128/JVI.78.12.6233-6242.2004.

20. Chen R, Neill JD, Estes MK, Prasad BV. 2006. X-ray structure of a native calicivirus: structural insights into antigenic diversity and host specificity. Proc Natl Acad Sci U S A 103:8048-8053. https://doi.org/10.1073/pnas .0600421103 .

21. Hansman GS, Taylor DW, McLellan JS, Smith TJ, Georgiev I, Tame JR, Park SY, Yamazaki M, Gondaira F, Miki M, Katayama K, Murata K, Kwong PD. 2012. Structural basis for broad detection of genogroup II noroviruses by a monoclonal antibody that binds to a site occluded in the viral particle. J Virol 86:3635-3646. https://doi.org/10.1128/JVI.06868-11.

22. Wang X, Xu F, Liu J, Gao B, Liu Y, Zhai Y, Ma J, Zhang K, Baker TS, Schulten K, Zheng D, Pang H, Sun F. 2013. Atomic model of rabbit hemorrhagic disease virus by cryo-electron microscopy and crystallography. PLoS Pathog 9:e1003132. https://doi.org/10.1371/journal.ppat .1003132.

23. Koromyslova A, Tripathi S, Morozov V, Schroten H, Hansman GS. 2017. Human norovirus inhibition by a human milk oligosaccharide. Virology 508:81-89. https://doi.org/10.1016/j.virol.2017.04.032.

24. Koromyslova AD, Morozov VA, Hefele L, Hansman GS. 2018. Human norovirus neutralized by a monoclonal antibody targeting the histoblood group antigen pocket. J Virol 93:e02174-18. https://doi.org/10 .1128/JVI.02174-18.

25. Lindesmith LC, Mallory ML, Debbink K, Donaldson EF, Brewer-Jensen PD, Swann EW, Sheahan TP, Graham RL, Beltramello M, Corti D, Lanzavecchia A, Baric RS. 2018. Conformational occlusion of blockade antibody epitopes, a novel mechanism of Gll.4 human norovirus immune evasion. mSphere 3:e00518-17. https://doi.org/10.1128/mSphere.00518-17.

26. Lindesmith LC, McDaniel JR, Changela A, Verardi R, Kerr SA, Costantini V, Brewer-Jensen PD, Mallory ML, Voss WN, Boutz DR, Blazeck JJ, Ippolito GC, Vinje J, Kwong PD, Georgiou G, Baric RS. 2019. Sera antibody repertoire analyses reveal mechanisms of broad and pandemic strain neutralizing responses after human norovirus vaccination. Immunity 50:1530-1541.e1538. https://doi.org/10.1016/j.immuni.2019.05.007.

27. Ruoff K, Kilic T, Devant J, Koromyslova A, Ringel A, Hempelmann A, Geiss C, Graf J, Haas M, Roggenbach I, Hansman G. 2019. Structural basis of nanobodies targeting the prototype norovirus. J Virol 93:e02005-18. https://doi.org/10.1128/JVI.02005-18.

28. Shanker S, Czako R, Sapparapu G, Alvarado G, Viskovska M, Sankaran B, Atmar RL, Crowe JE, Jr, Estes MK, Prasad BV. 2016. Structural basis for norovirus neutralization by an HBGA blocking human $\lg A$ antibody. Proc Natl Acad Sci U S A 113:E5830-E5837. https://doi.org/10.1073/pnas .1609990113 .

29. Katpally U, Wobus CE, Dryden K, Virgin H. W t, Smith TJ. 2008. Structure of antibody-neutralized murine norovirus and unexpected differences from viruslike particles. J Virol 82:2079-2088. https://doi.org/10.1128/JVI .02200-07.

30. Kolawole AO, Smith HQ, Svoboda SA, Lewis MS, Sherman MB, Lynch GC, Pettitt BM, Smith TJ, Wobus CE. 2017. Norovirus escape from broadly neutralizing antibodies is limited to allostery-like mechanisms. mSphere 2:e00334-17. https://doi.org/10.1128/mSphere.00334-17.
31. Taube S, Rubin JR, Katpally U, Smith TJ, Kendall A, Stuckey JA, Wobus CE. 2010. High-resolution x-ray structure and functional analysis of the murine norovirus 1 capsid protein protruding domain. J Virol 84: 5695-5705. https://doi.org/10.1128/JVI.00316-10.

32. Koromyslova AD, Hansman GS. 2017. Nanobodies targeting norovirus capsid reveal functional epitopes and potential mechanisms of neutralization. PLoS Pathog 13:e1006636. https://doi.org/10.1371/journal.ppat .1006636 .

33. Koromyslova AD, Hansman GS. 2015. Nanobody binding to a conserved epitope promotes norovirus particle disassembly. J Virol 89:2718-2730. https://doi.org/10.1128/JVI.03176-14.

34. Sherman MB, Williams AN, Smith HQ, Nelson C, Wilen CB, Fremont DH, Virgin HW, Smith TJ. 2019. Bile salts alter the mouse norovirus capsid conformation: possible implications for cell attachment and immune evasion. J Virol 93:e00970-19. https://doi.org/10.1128/JVI.00970-19.

35. Rohayem J, Bergmann M, Gebhardt J, Gould E, Tucker P, Mattevi A, Unge T, Hilgenfeld R, Neyts J. 2010. Antiviral strategies to control calicivirus infections. Antiviral Res 87:162-178. https://doi.org/10.1016/j.antiviral .2010.05.002.

36. Feng X, Jiang X. 2006. Library screen for inhibitors targeting norovirus binding to their histo-blood group antigen receptors. Antimicrob Agents Chemother 51:324-331. https://doi.org/10.1128/AAC.00627-06.

37. Horm KM, Davidson PM, Harte FM, D'Souza DH. 2012. Survival and inactivation of human norovirus surrogates in blueberry juice by highpressure homogenization. Foodborne Pathog Dis 9:974-979. https://doi .org/10.1089/fpd.2012.1171.

38. Li D, Baert L, Zhang D, Xia M, Zhong W, Van Coillie E, Jiang X, Uyttendaele M. 2012. Effect of grape seed extract on human norovirus GII.4 and murine norovirus 1 in viral suspensions, on stainless steel discs, and in lettuce wash water. Appl Environ Microbiol 78:7572-7578. https://doi .org/10.1128/AEM.01987-12.

39. Rademacher C, Guiard J, Kitov PI, Fiege B, Dalton KP, Parra F, Bundle DR, Peters T. 2011. Targeting norovirus infection-multivalent entry inhibitor design based on NMR experiments. Chemistry 17:7442-7453. https://doi .org/10.1002/chem.201003432.

40. Su X, Howell AB, D'Souza DH. 2010. The effect of cranberry juice and cranberry proanthocyanidins on the infectivity of human enteric viral surrogates. Food Microbiol 27:535-540. https://doi.org/10.1016/j.fm .2010.01.001.

41. Hansman GS, Shahzad-UI-Hussan S, McLellan JS, Chuang GY, Georgiev I, Shimoike T, Katayama K, Bewley CA, Kwong PD. 2012. Structural basis for norovirus inhibition and fucose mimicry by citrate. J Virol 86:284-292. https://doi.org/10.1128/JVI.05909-11.

42. Koromyslova AD, White PA, Hansman GS. 2015. Treatment of norovirus particles with citrate. Virology 485:199-204. https://doi.org/10.1016/j virol.2015.07.009.

43. Weichert S, Koromyslova A, Singh BK, Hansman S, Jennewein S, Schroten H, Hansman GS. 2016. Structural basis for norovirus inhibition by human milk oligosaccharides. J Virol 90:4843-4848. https://doi.org/10.1128/JVI .03223-15.

44. Chen Z, Sosnovtsev SV, Bok K, Parra Gl, Makiya M, Agulto L, Green KY, Purcell RH. 2013. Development of Norwalk virus-specific monoclonal antibodies with therapeutic potential for the treatment of Norwalk virus gastroenteritis. J Virol 87:9547-9557. https://doi.org/10.1128/JVI .01376-13.

45. Czako R, Atmar RL, Opekun AR, Gilger MA, Graham DY, Estes MK. 2012. Serum hemagglutination inhibition activity correlates with protection from gastroenteritis in persons infected with Norwalk virus. Clin Vaccine Immunol 19:284-287. https://doi.org/10.1128/CVI.05592-11.

46. Lindesmith LC, Ferris MT, Mullan CW, Ferreira J, Debbink K, Swanstrom J, Richardson C, Goodwin RR, Baehner F, Mendelman PM, Bargatze RF, Baric RS. 2015. Broad blockade antibody responses in human volunteers after immunization with a multivalent norovirus VLP candidate vaccine: immunological analyses from a phase I clinical trial. PLoS Med 12: e1001807. https://doi.org/10.1371/journal.pmed.1001807.

47. Li PP, Naknanishi A, Tran MA, Ishizu K, Kawano M, Phillips M, Handa H, Liddington RC, Kasamatsu H. 2003. Importance of Vp1 calcium-binding residues in assembly, cell entry, and nuclear entry of simian virus $40 . \mathrm{J}$ Virol 77:7527-7538. https://doi.org/10.1128/jvi.77.13.7527-7538.2003.

48. Jin J, Liss NM, Chen DH, Liao M, Fox JM, Shimak RM, Fong RH, Chafets D, Bakkour S, Keating S, Fomin ME, Muench MO, Sherman MB, Doranz BJ, Diamond MS, Simmons G. 2015. Neutralizing monoclonal antibodies block chikungunya virus entry and release by targeting an epitope 
critical to viral pathogenesis. Cell Rep 13:2553-2564. https://doi.org/10 .1016/j.celrep.2015.11.043.

49. Ohizumi Y, Suzuki H, Matsumoto Y-I, Masuho Y, Numazaki Y. 1992. Neutralizing mechanisms of two human monoclonal antibodies against human cytomegalovirus glycoprotein 130/55. The J General Virology 73:2705-2707. https://doi.org/10.1099/0022-1317-73-10-2705.

50. Vrijsen R, Mosser A, Boeyé A. 1993. Postadsorption neutralization of poliovirus. J Virol 67:3126-3133. https://doi.org/10.1128/JVI.67.6.3126 $-3133.1993$.

51. Rossey I, Gilman MS, Kabeche SC, Sedeyn K, Wrapp D, Kanekiyo M, Chen M, Mas V, Spitaels J, Melero JA, Graham BS, Schepens B, McLellan JS, Saelens X. 2017. Potent single-domain antibodies that arrest respiratory syncytial virus fusion protein in its prefusion state. Nat Commun 8:16165. https://doi.org/10.1038/ncomms14158.

52. Spenlehauer C, Kirn A, Aubertin AM, Moog C. 2001. Antibody-mediated neutralization of primary human immunodeficiency virus type 1 isolates: investigation of the mechanism of inhibition. J Virol 75:2235-2245. https://doi.org/10.1128/JVI.75.5.2235-2245.2001.

53. Reisdorph N, Thomas JJ, Katpally U, Chase E, Harris K, Siuzdak G, Smith TJ. 2003. Human rhinovirus capsid dynamics is controlled by canyon flexibility. Virology 314:34-44. https://doi.org/10.1016/S0042-6822(03) 00452-5.

54. Smith TJ, Kremer MJ, Luo M, Vriend G, Arnold E, Kamer G, Rossmann MG, McKinlay MA, Diana GD, Otto MJ. 1986. The site of attachment in human rhinovirus 14 for antiviral agents that inhibit uncoating. Science 233: 1286-1293. https://doi.org/10.1126/science.3018924.

55. Ettayebi K, Crawford SE, Murakami K, Broughman JR, Karandikar U, Tenge VR, Neill FH, Blutt SE, Zeng XL, Qu L, Kou B, Opekun AR, Burrin D, Graham DY, Ramani S, Atmar RL, Estes MK. 2016. Replication of human noroviruses in stem cell-derived human enteroids. Science 353: 1387-1393. https://doi.org/10.1126/science.aaf5211.

56. Murakami K, Tenge VR, Karandikar UC, Lin S-C, Ramani S, Ettayebi K, Crawford SE, Zeng X-L, Neill FH, Ayyar BV, Katayama K, Graham DY, Bieberich E, Atmar RL, Estes MK. 2020. Bile acids and ceramide overcome the entry restriction for Gll.3 human norovirus replication in human intestinal enteroids. Proc Natl Acad Sci U S A 117:1700-1710. https:// doi.org/10.1073/pnas.1910138117.

57. Tai CJ, Li CL, Tai CJ, Wang CK, Lin LT. 2015. Early viral entry assays for the identification and evaluation of antiviral compounds. J Vis Exp e53124. https://doi.org/10.3791/53124.
58. McCoy AJ, Grosse-Kunstleve RW, Adams PD, Winn MD, Storoni LC, Read RJ. 2007. Phaser crystallographic software. J Appl Crystallogr 40: 658-674. https://doi.org/10.1107/S0021889807021206.

59. Kabsch W. 2010. XDS. Acta Crystallogr D Biol Crystallogr 66:125-132. https://doi.org/10.1107/S0907444909047337.

60. Emsley P, Lohkamp B, Scott WG, Cowtan K. 2010. Features and development of Coot. Acta Crystallogr D Biol Crystallogr 66:486-501. https:// doi.org/10.1107/S0907444910007493.

61. Vagin AA, Steiner RA, Lebedev AA, Potterton L, McNicholas S, Long F, Murshudov GN. 2004. REFMAC5 dictionary: organization of prior chemical knowledge and guidelines for its use. Acta Crystallogr D Biol Crystallogr 60:2184-2195. https://doi.org/10.1107/S0907444904023510.

62. Winn MD, Ballard CC, Cowtan KD, Dodson EJ, Emsley P, Evans PR, Keegan RM, Krissinel EB, Leslie AGW, McCoy A, McNicholas SJ, Murshudov GN, Pannu NS, Potterton EA, Powell HR, Read RJ, Vagin A, Wilson KS. 2011. Overview of the CCP4 suite and current developments. Acta Crystallogr D Biol Crystallogr 67:235-242. https://doi.org/ 10.1107/S0907444910045749.

63. Chen VB, Arendall WB, III, Headd JJ, Keedy DA, Immormino RM, Kapral GJ, Murray LW, Richardson JS, Richardson DC. 2010. MolProbity: all-atom structure validation for macromolecular crystallography. Acta Crystallogr D Biol Crystallogr 66:12-21. https://doi.org/10.1107/ S0907444909042073.

64. Persson S, Eriksson R, Lowther J, Ellstrom P, Simonsson M. 2018. Comparison between RT droplet digital PCR and RT real-time PCR for quantification of noroviruses in oysters. Int J Food Microbiol 284:73-83. https://doi.org/10.1016/j.jifoodmicro.2018.06.022.

65. Scheres SHW. 2012. RELION: implementation of a Bayesian approach to cryo-EM structure determination. J Struct Biol 180:519-530. https://doi .org/10.1016/j.jsb.2012.09.006.

66. Conley MJ, McElwee M, Azmi L, Gabrielsen M, Byron O, Goodfellow IG, Bhella D. 2019. Calicivirus VP2 forms a portal-like assembly following receptor engagement. Nature 565:377-381. https://doi.org/10.1038/ s41586-018-0852-1.

67. Frank J, Radermacher M, Penczek P, Zhu J, Li Y, Ladjadj M, Leith A. 1996. SPIDER and WEB: processing and visualization of images in 3D electron microscopy and related fields. J Struct Biol 116:190-199. https://doi.org/ 10.1006/jsbi.1996.0030. 